\title{
The Heavy Rainfall Mechanism Revealed by a Terrain-Resolving 4DVar Data Assimilation System-A Case Study
}

\author{
SHENG-LUN TAI \\ Pacific Northwest National Laboratory, Richland, Washington, and Department of Atmospheric Sciences, \\ National Central University, Taoyuan, Taiwan \\ Yu-CHIENG LIOU AND SHAO-FAN CHANG \\ Department of Atmospheric Sciences, National Central University, Taoyuan, Taiwan \\ JUANZHEN SUN \\ National Center for Atmospheric Research, Boulder, Colorado
}

(Manuscript received 24 July 2019, in final form 31 March 2020)

\begin{abstract}
In this research a newly developed terrain-resolving four-dimensional variational (4DVar)-based data assimilation system, Immersed Boundary Method_Variational Doppler Radar Analysis System (IBM_VDRAS), is applied to investigate the mechanisms leading to a heavy precipitation event that occurred in Taiwan during the Southwesterly Monsoon Experiment (SoWMEX) conducted in 2008. The multivariate analyses using IBM_VDRAS and surface observations reveal that the warm and moist southwesterly flow from the ocean decelerates after making landfall, forming a surface convergence zone along the coast, which is further strengthened during the passage of a prefrontal rainband. The flow ascends as it advances inland until reaching the mountains, producing persistent precipitation and the enhancement of evaporative cooling as well as a widespread high pressure zone. A very shallow $(<0.4 \mathrm{~km})$ layer of offshore flow can be identified over the southwestern plain, which helps to generate a quasi-stationary convergence zone near the coast. Sensitivity studies are carried out to quantify the relative importance of the contributions made by topographic blockage, evaporative cooling, and their nonlinear interaction, to the evolution of this type of convective system. The influence of the topography is identified as the dominant factor in modulating the flow structure of the rainfall system. However, it is the nonlinear interaction between terrain and evaporation that determines the distribution of the temperature and pressure fields.
\end{abstract}

\section{Introduction}

The processes associated with the influence of the terrain on convective systems are complicated. The characteristics of the mountains, the direction and intensity of the incoming wind, the thermodynamical and microphysical properties of the atmosphere, the size and height of the convective cells, and large-scale forcing, are the key factors influencing the formation, enhancement and maintenance of rainfall as air passes over the mountains (Markowski and Richardson 2010). In the literature one can find numerous studies in which different approaches, including theoretical analyses,

\footnotetext{
Corresponding author: Dr. Yu-Chieng Liou, tyliou@atm.ncu. edu.tw
}

numerical modeling and/or observational data have been utilized to study the characteristics and prediction of orographically induced precipitation. For example, by developing a linear theory, Smith and Barstad (2004) found precipitation efficiency to be strongly affected by decay of the forced ascent through the moist layer and by the advection of condensed water downwind into the descent region. Chen and Lin (2005) performed idealized numerical simulations using the Weather Research and Forecasting (WRF) Model, showing that the Coriolis force and the associated flow deflection could help to produce heavy rainfall on the upslope, rather than at the mountain peak or on the lee side. Chen et al. (2013) carried out numerical simulations to find that the amount of low-level moisture and the orographic effects were equally important for the formation 
and maintenance of heavy rainfall. Evolution of mountain waves at different mountain heights was examined in numerical simulations conducted by Menchaca and Durran (2017). They found large spatial variations in wave structure and downslope winds despite the uniformity of the terrain profile.

Moving toward the study of orographic effect from a more observational perspective, Lin et al. (2001) identified the common synoptic and mesoscale environments favorable for heavy orographic rainfall. They also designed an index for predicting heavy orographic rainfall in East Asia. Rotunno and Houze (2007) analyzed the results obtained from the Mesoscale Alpine Programme (MAP; Bougeault et al. 2001), and pointed out that for a complete understanding of the orographically modified airflow, factors such as synoptic conditions, low-level static stability, latent heat release, and mountain shape need to be considered. Wulfmeyer et al. (2011) provided an overview of an international field campaign known as Convective and Orographically-induced Precipitation Study (COPS). They discussed the spatial and temporal distribution of precipitation during the experiment, the process chain leading to convection initiation $(\mathrm{CI})$, the formation of cloud and precipitation, the mesoscale and thermodynamically induced flow, and the results from data assimilation experiments. Weckwerth et al. (2014) demonstrated in a case study that the initiation of moist convection was closely related to the low-level moisture and uplift caused by shallow, colliding boundary layer flows. Reviews regarding the basic mechanisms responsible for orographic precipitation can be found in Roe (2005) and Houze (2012).

The Southwesterly Monsoon Experiment (SoWMEX) was conducted from May to June of 2008 in southern Taiwan. The scientific purpose of this field campaign was to understand the kinematic and thermodynamic characteristics of the prevailing southwesterly flows, the physical processes leading to intensive orographic rainfalls, and the mechanisms that produced heavy precipitation in the South China Sea and Taiwan area during the Asian summer monsoon season. Numerous research results have already been published. Lai et al. (2011) reported on the formation of a subtropical oceanic mesoscale convective vortex observed during intensive observation period (IOP) 6 . They found that it was a dissipating mesoscale convective system (MCS) reorganized within a southwesterly low-level jet. The southerly flow induced by the vortex helped to generate potential instability favorable for convection enhancement. Chang et al. (2015) computed the precipitation efficiency of a prefrontal squall line and a southwesterly monsoon MCS, and explored the dependence of precipitation efficiency on the environmental and microphysical factors. Davis and Lee (2012) documented the presence of a coastal boundary near southwestern Taiwan during the IOP 8 , and concluded that it was caused by the thermal contrast. Xu et al. (2012) identified a low-level jet (LLJ) over the upstream ocean, which was lifted at the boundary between the LLJ and the cold pool. New convection kept developing over the ocean, but decayed after moving downstream onto the land, producing heavy rain over the upstream ocean as well as coastal regions. The mountains in Taiwan helped to keep the cold pool from spreading or moving. As a result, the orography of Taiwan was "extended" to the upstream ocean, playing an indirect effect on the long-lasting mesoscale system. Recently, Tu et al. (2017) demonstrated that for a successful prediction of heavy rainfall during IOP 8 , it is crucial for the numerical model to be able to resolve the warm moist tongue and southwesterly monsoon flow over the open ocean, the cold pool caused by the evaporative cooling of antecedent rains, and orographic blocking over southwestern Taiwan.

Although several possible mechanisms have been identified above, our research goal is to quantitatively diagnose the relative importance of different factors for the maintenance of a heavy rainfall event that occurred during SoWMEX. In addition to studying the cooling and topographic effects separately, this study also aims to find out how their interaction can influence a precipitating system. The methodology utilized for this purpose is an advanced four-dimensional variational (4DVar) data assimilation system, which is capable of optimally merging data from different sources, including observations and numerical model outputs, and generate the best description of the status of the atmosphere.

The Variational Doppler Radar Analysis System (VDRAS), developed at the National Center for Atmospheric Research (NCAR), is a convective-scale weather radar data assimilation system designed to produce high-resolution analyses for the detailed study of convective weather. Recently, Tai et al. (2017) significantly improved VDRAS by including topographic effects through the implementation of the so-called Immersed Boundary Method (IBM) to handle the bottom boundary conditions. This newly developed system, called IBM_VDRAS, is able to produce high spatiotemporal resolution meteorological fields directly over complex terrain. The products generated by IBM_VDRAS are utilized in this study to investigate the mechanisms leading to a heavy precipitation event in Taiwan during SoWMEX.

The rest of this manuscript is organized as follows. The IBM_VDRAS, including its cost function, forward forecast model, and data assimilation concept is briefly introduced in section 2. Section 3 explains the data sources used 
for this study. Section 4 offers an overview of the heavy rainfall event to be explored in this study. The experimental design and data assimilation strategy are presented in section 5. A discussion of the verification of the IBM_VDRAS analysis fields using other independent observational data can be found in section 6 . Section 7 shows the results obtained from the multivariate analyses using the high spatiotemporal analysis fields generated by IBM_VDRAS and provides a summary regarding the heavy rainfall processes involved in this case study. The sensitivity studies are discussed in section 8 to identify the roles played by different factors, followed by the conclusions and plans for future work in section 9.

\section{A brief introduction of IBM_VDRAS}

VDRAS uses a cloud-resolving forecast model as a constraint to search for an optimal initial condition that can minimize the differences between model forecasts and observations within the assimilation window(s). This model employs the Kessler-type warm rain process (Kessler 1969) and a simple ice scheme (Chang et al. 2016), but only the former is utilized in this study. As listed in Tai et al. (2017), VDRAS comprises six prognostic equations, including three momentum equations, the thermodynamic equation, the rainwater equation, and the total water equation. The original version is formulated in a Cartesian coordinate. The 4DVar technique is employed to assimilate radar observations, including the Doppler radial velocity and reflectivity. As shown by Tai et al. (2017), a cost function is defined to measure the differences between the model-produced and radar-observed radial winds and rainwater mixing ratio,

$$
\begin{aligned}
J= & \frac{1}{2}\left(\mathbf{x}_{0}-\mathbf{x}_{b}\right)^{\mathrm{T}} \mathbf{B}^{-1}\left(\mathbf{x}_{0}-\mathbf{x}_{b}\right)+\frac{1}{2} \sum_{\sigma, t}\left[\eta_{v}\left(V_{r}-V_{r}^{o}\right)^{2}\right. \\
& \left.+\eta_{q}\left(q_{r}-q_{r}^{o}\right)^{2}\right]+J_{p}+J_{\mathrm{mb}},
\end{aligned}
$$

where $\mathbf{x}_{0}$ is the analysis of the model variables at the beginning of the assimilation window, $\mathbf{x}_{b}$ is the background field, and $\mathbf{B}$ denotes the background error covariance matrix. Similar to Chang et al. (2016), a recursive filter (Hayden and Purser 1995) is applied to model the spatial covariance in VDRAS. The second term on the right-hand side of (1) represents the discrepancy between the model-produced radial velocity $\left(V_{r}\right)$ and rainwater mixing ratio $\left(q_{r}\right)$ obtained from their radar-observed counterparts $V_{r}^{o}$ and $q_{r}^{o}$, respectively. The latter can be estimated from the radar reflectivity through an empirical relationship, as described by Sun and Crook (1997). It is assumed that there is no spatial correlation between observations, and the summation in $(1)$ is over all observations in the analysis domain $(\sigma)$ and time $(t)$ within a specified assimilation window. The coefficients $\eta_{v}$ and $\eta_{q}$ are inversely proportional to the observational error variances for radial velocity and rainwater, and are given values of 1 and 50, respectively. Thus, information from the observational data is spread through the model integration implicitly. The third term $\left(J_{p}\right)$ is a smoothness term designed to remove nonphysical gradients in time and space introduced by the inclusion of observations. The final term $J_{\mathrm{mb}}$ stands for a mesoscale background field, which provides larger-scale information to fill in the radar data-void regions.

The VDRAS analysis fields comprise a set of high spatiotemporal resolution three-dimensional model state variables such as winds, thermodynamic fields, and microphysical parameters. Tai et al. (2017) pointed out that compared to other 4DVar systems (e.g., Kawabata et al. 2011; Sun and Wang 2013; Wang et al. 2013; Ballard et al. 2016), VDRAS is designed specifically for analyzing storm-scale weather systems and nowcasting, having the capability to provide frequently updated high spatial resolution analysis fields (Chang et al. 2014, 2016). VDRAS has been applied in a variety of studies, ranging from low-level wind and temperature field retrieval (Sun and Crook 2001), initialization and forecast of supercells (Sun 2005), near-real-time operational utilization during special events such as the Olympic Games in Sydney and Beijing (Crook and Sun 2002, 2004; Sun et al. 2010), radar radial wind quality control (Lim and Sun 2010), short-term rainfall forecast (Sun and Zhang 2008; Tai et al. 2011; Chang et al. 2016), and investigation of the genesis of heavy precipitation (Friedrich et al. 2016; Gochis et al. 2015).

Despite the successful promising applications of the VDRAS system, Tai et al. (2011) showed that the inability of VDRAS to resolve complex terrain significantly degrades its capacity for analysis and forecasting over mountainous regions. For weather systems over complex terrain, it is necessary to develop a terrainresolving scheme for VDRAS, by which one can assimilate radar data, and perform rapidly updated analyses as well as forecast directly over areas with complex topography.

The Immersed Boundary Method (IBM) was implemented into VDRAS to allow it to conduct simulations and data assimilation over nonflat terrain without the necessity of transforming the coordinates, meaning that one can still keep the Cartesian Coordinates (Tseng and Ferziger 2003; Yamazaki and Satomura 2010). In simulations of the flow over buildings in downtown New York City, Lundquist et al. (2010) demonstrated that the IBM can handle very rugged bottom boundary such as 


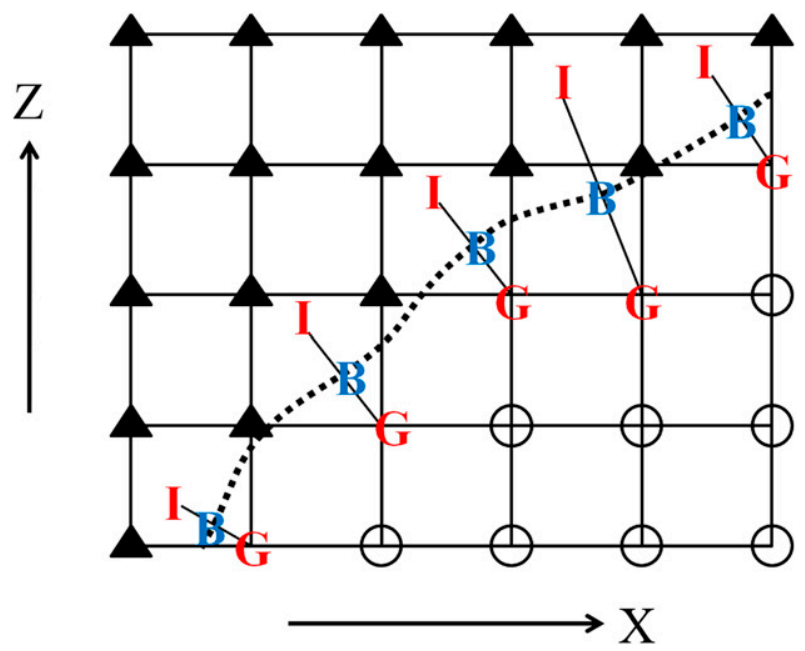

FIG. 1. The $X-Z$ two-dimensional example of the IBM gridpoint system used in this study. The thick dashed line represents the terrain surface. Grids in the flow regime are marked with filled triangles, while grids inside the terrain are plotted by open circles. Locations of ghost cell grids, boundary points, and image points are connected with lines perpendicular to the terrain surface, indicated by the letters "G," "B," and "I," respectively. The image points are introduced to maintain the computational stability.

urban surface, which is difficult for a model employing a standard terrain-following coordinate. Figure 1 provides a two-dimensional example of the IBM gridpoint system used in this study. The ghost cells are defined as the first point immediately inside the terrain when searching in the vertical (from the top) and horizontal (from the flow regime) directions, respectively. As introduced in Tai et al. (2017), the IBM approach considers the topographic effects by updating the nodes near the nonflat surface (i.e., points labeled $\mathrm{G}$ and I in Fig. 1), while certain suitable boundary conditions (i.e., Neumann or Dirichlet type) are forced to be satisfied along the terrain surface (points marked B in Fig. 1). In this study, the Ghost Cell Immersed Boundary Method (GCIBM) proposed by Mohd-Yusof (1997) and Tseng and Ferziger (2003) is selected. Details about the implementation of IBM in VDRAS and experimental results demonstrating the accuracy of the new system can be found in Tai et al. (2017). The newly developed IBM_VDRAS data assimilation system is utilized to analyze the major precipitation processes involved in a heavy rainfall event which took place in Taiwan.

\section{Data sources for the mesoscale background and assimilation}

Figure 2 shows the data sources utilized to produce the mesoscale background field for IBM_VDRAS and

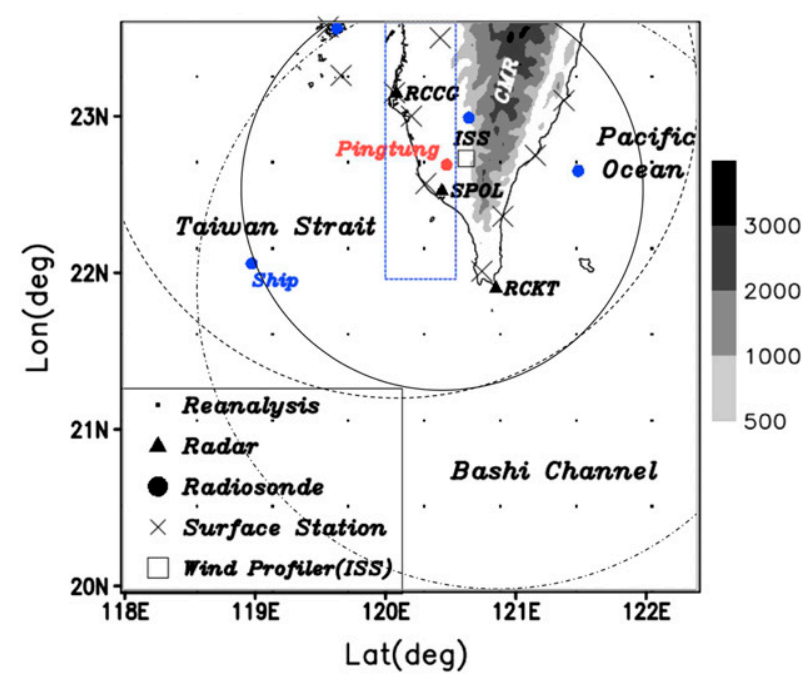

FIG. 2. Locations of data collected from different sources. Triangles indicate radars (RCCG, RCKT, SPOL). The solid circles are radiosondes, with the red one representing Pingtung station. The sounding released from a research ship is also marked. The crosses stand for mesonet stations, while the small dots denote reanalysis data points from the ECMWF reanalysis, and the square shows the location of the ISS wind profiler. The rectangle enclosed by blue dashed line depicts the region in which the IBM_VDRAS wind analyses are verified using radar radial wind observations in the same area. The topography of the Central Mountain Range (CMR) is indicated by gray shading in units of meters. Circles plotted by dashed, solid, and dotted-dashed lines indicate the detection ranges for the RCCG, SPOL, and RCKT radars, respectively. The area shown in this figure is also the analysis domain employed by the IBM_VDRAS model.

to verify the analysis fields. They include radiosonde, mesonet station, weather radar, wind profiler, and reanalysis data obtained from the European Centre for MediumRange Weather Forecasts (ECMWF). The ECMWF data consist of wind, pressure, humidity, and temperature, and are interpolated and evenly distributed in the domain of interest. In addition to two CWB operational S-band radars, RCCG and RCKT, the S-band dual-polarimetric radar (S-POL) from NCAR are also deployed. Before being formally integrated into IBM_VDRAS, radar data quality control (QC) processes are conducted to unfold the radial wind and remove the ground clutter.

\section{The heavy rainfall event}

\section{a. An overview of the synoptic environment}

On 14 June 2008, a 500-hPa trough and 850-hPa low pressure area could be seen in eastern China (Figs. 3a,b). This synoptic pattern resulted in strong low-level southwesterly flow (Fig. 3c), which transported warm moist air from the South China Sea northeastward to Taiwan and adjacent areas. Later on 14 June, a mei-yu 
(a) $500 \mathrm{hPa}$

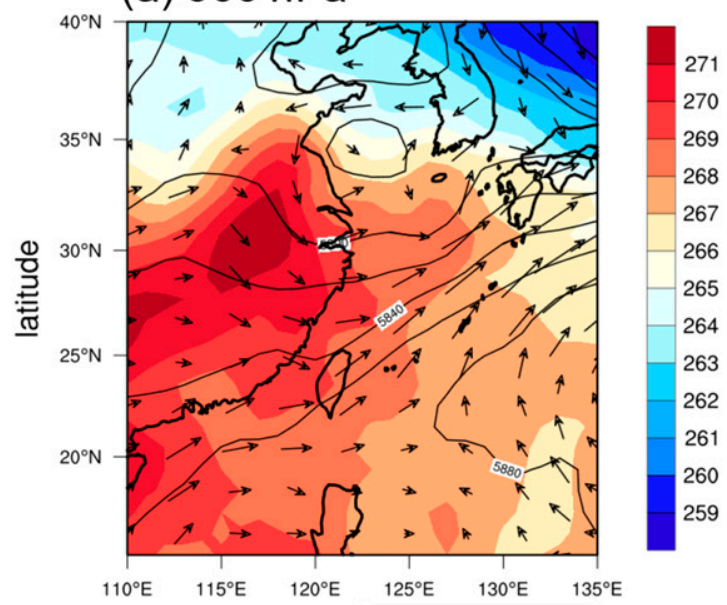

(b) $850 \mathrm{hPa}$

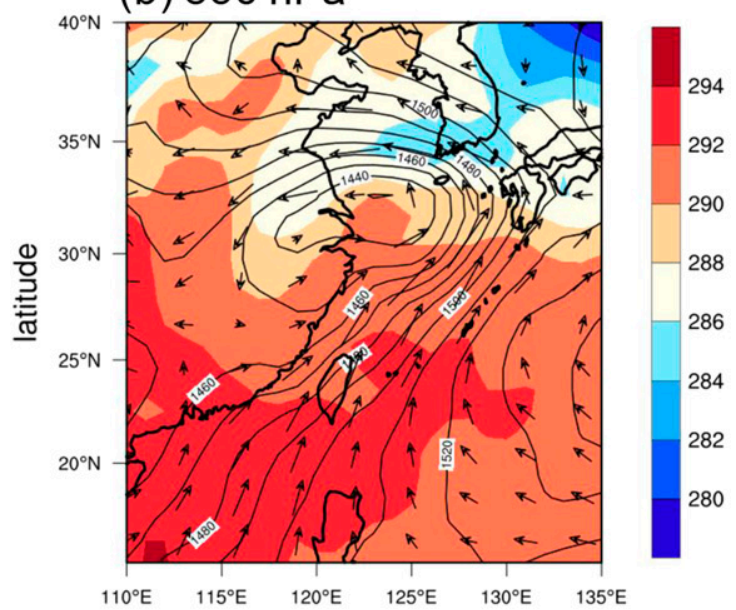

(c) $1000 \mathrm{hPa}$

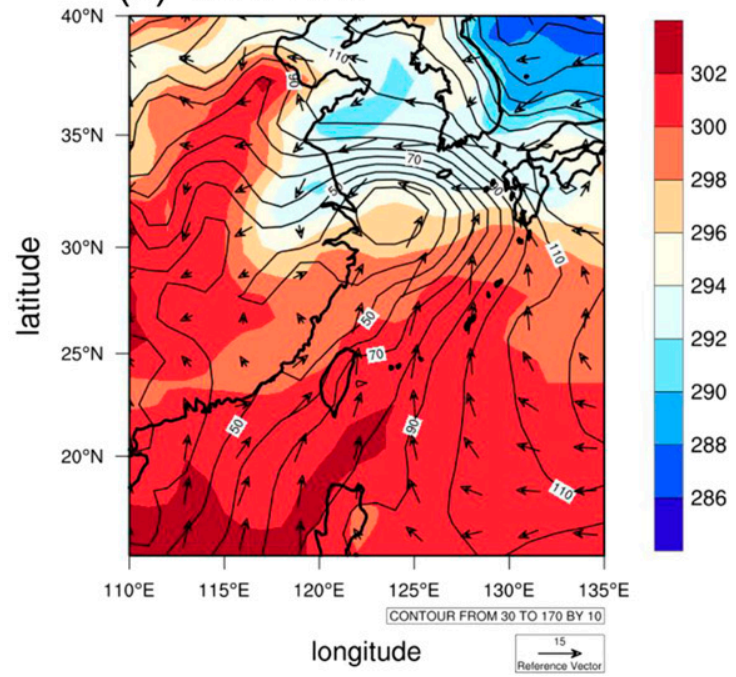

FIG. 3. Weather analysis over East Asia at 1200 UTC 14 Jun 2008 at (a) 500, (b) 850 , and (c) $1000 \mathrm{hPa}$ from NCEP FNL reanalysis data. Color shading represents temperature in $\mathrm{K}$, while contour lines denote geopotential height in meter. front moved southeastward and approached Taiwan (not shown). Ahead of the front, warm advection caused an increase in convective instability, which initiated and enhanced the prefrontal convective systems, producing heavy precipitation over the island.

\section{b. Evolution of the prefrontal rainbands}

The case selected for application of IBM_VDRAS analysis is from IOP 8 of SoWMEX, starting at 0000 UTC 14 June and ending at 0000 UTC 16 June. On 14 June, a prefrontal squall-line system and accompanying rainbands passed over Taiwan causing an accumulation of daily rainfall over southwestern Taiwan in excess of $100 \mathrm{~mm}$ (not shown). From 1100 to 1300 UTC (1900 to 2100 LST) 14 June, three major line-shaped convection systems were present near southern Taiwan, according to radar reflectivity observed by the Taiwan Central Weather Bureau's (CWB) operational S-band Doppler radar network. They are labeled A, B, and C in Fig. 4. At the initial time of the study period, rainband $B$ extended from the ocean to the north-south-oriented Central Mountain Range (CMR; see Fig. 2), almost parallel to the southwesterly flow. Later, rainbands A and $\mathrm{B}$ became elongated in a northeast (NE)-southwest (SW) direction, moving toward the southeast to produce extensive rainfall over southern Taiwan. The rainfall accumulated over a 2 -h period, as recorded by CWB rain gauges and shown in Fig. 5, indicated significantly heavy rainfall, especially on the windward side (west) of the CMR. The precipitation exceeded $40 \mathrm{~mm}$ near the coast, with the pattern extending toward the northeast.

\section{Experimental design and assimilation strategy}

To capture the evolution of the rainbands, IBM VDRAS was run in continuous cycles from 1022 to 1257 UTC 14 June 2008. The spatial resolutions of the model grid are 2.0 and $0.5 \mathrm{~km}$ in the horizontal and vertical directions, respectively. The domain dimensions along the three axes are $X=230, Y=200$, and $Z=30$, covering southern Taiwan and the upstream ocean to a maximum height of $14.75 \mathrm{~km}$, as shown in Fig. 2. The assimilation strategy is illustrated in Fig. 6. As recommended in Sun and Zhang (2008), a pure model forecast is inserted between two assimilation cycles to improve the accuracy of the VDRAS retrievals. The first available analysis is generated at 1102 UTC, followed by five more analyses at time intervals of approximately $23 \mathrm{~min}$. These datasets are used to provide information about the evolution of the convective systems associated with the prefrontal rainbands. 

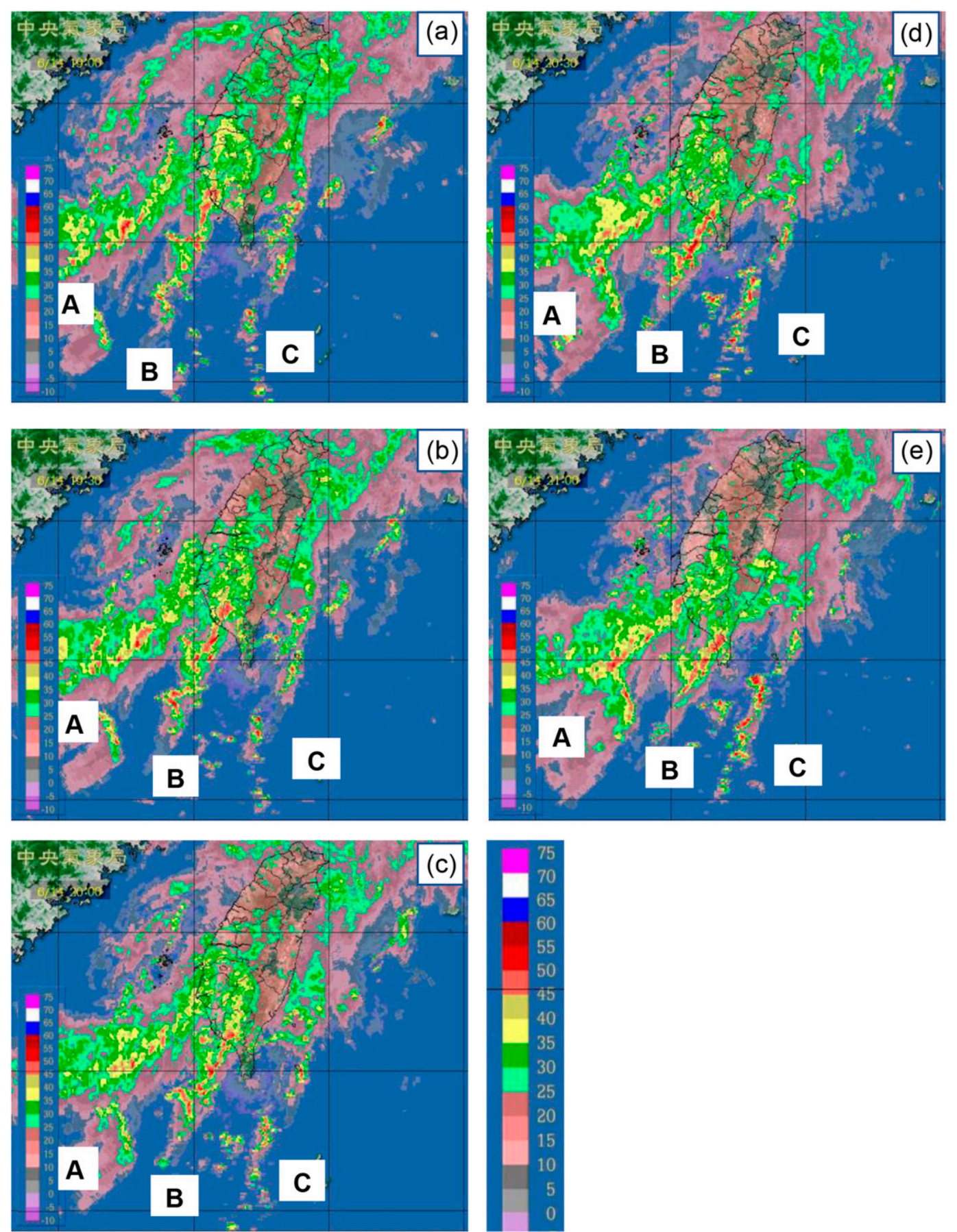

FIG. 4. Composite maximum reflectivity (color shading in $\mathrm{dBZ}$ ) observed by the Taiwan CWB radar network: (a)-(e) observations at 1100, 1130, 1200, 1230, and 1300 UTC 14 Jun 2008. Three major prefrontal rainbands are marked by $\mathrm{A}, \mathrm{B}$, and $\mathrm{C}$, respectively.

\section{Verification of IBM_VDRAS analysis}

A series of verifications are conducted to confirm the performance of the 4DVar minimization procedure of IBM_VDRAS and the accuracy of the analysis fields.

\section{a. Radar radial wind}

To make sure that minimization in the 4DVar assimilation cycles is performed normally so that the radar radial wind observations are properly assimilated into IBM_VDRAS, the three-dimensional wind fields 

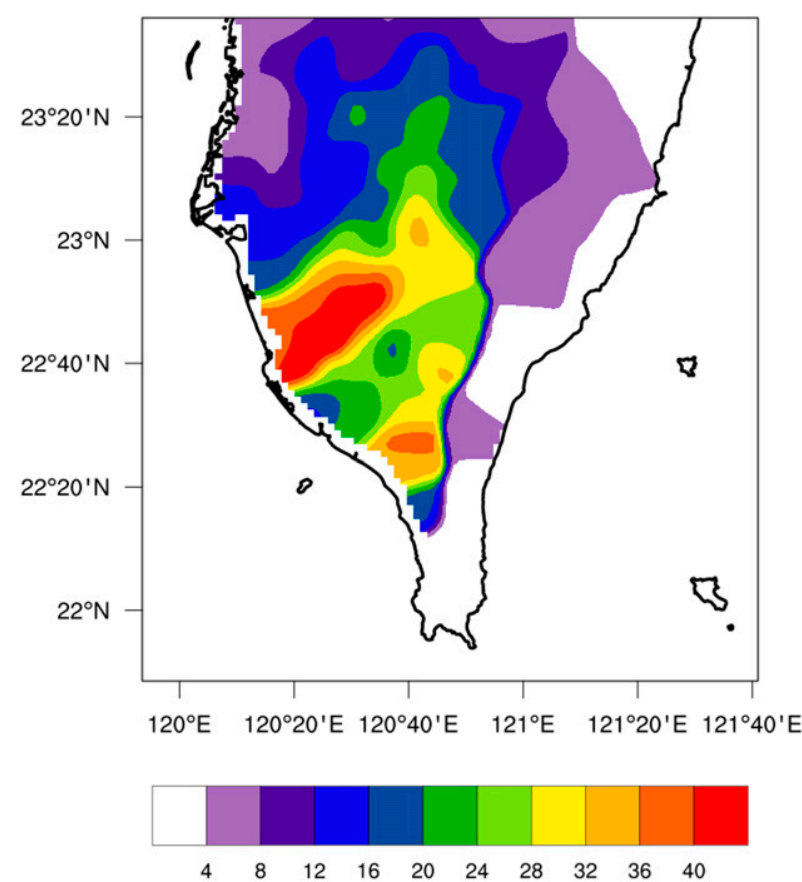

FIG. 5. The $2 \mathrm{~h}$ (from 1100 to 1300 UTC 14 Jun 2008) of accumulated rainfall $(\mathrm{mm})$ observed by Taiwan CWB rain gauges.

$(u, v, w)$ from IBM_VDRAS are projected onto the locations of RCCG observations (see Fig. 2) to obtain a set of model-generated radial winds $\left(V_{r}\right)$, which are then compared against the radar observed radial wind.

The indices, including the root-mean-square error (RMSE) and spatial correlation coefficient (SCC) are calculated. The SCC (for definitions see Liou and Chang 2009) is employed to access the degree of similarity between two fields. The verification domain covers an area ranging $21.96^{\circ}-23.6^{\circ} \mathrm{N}, 120^{\circ}-120.54^{\circ} \mathrm{E}$ (see Fig. 2) and is $0.25-9.75 \mathrm{~km}$ in height. A summary of the performance of continuous analyses over $2 \mathrm{~h}$ is shown in Fig. 7a. It can be seen that the SCC computed with RCCG observations can reach as high as 0.98 . The RMSEs at all analysis times are $2.0-3.0 \mathrm{~m} \mathrm{~s}^{-1}$, which are reasonably accurate, as the wind speed in the domain can reach well over $20 \mathrm{~m} \mathrm{~s}^{-1}$.

The radar reflectivity fields produced by IBM $_{-}$ VDRAS are also in good agreement with the observations. An example is illustrated in Fig. 7b showing the maximum radar reflectivity of each column at 1234 UTC from IBM_VDRAS. This figure exhibits a high degree of similarity to the composite radar observations at 1230 UTC displayed in Fig. 4d.

Overall, the results of SCC and RMSE for the radial velocity and comparison of reflectivity reveal that the wind and reflectivity analyses from IBM_VDARS are persistently of good quality, which is an indication that the radar data have been properly assimilated.

In the following sections, the accuracy of the IBM VDRAS analysis fields are verified using independent observations.

\section{b. Surface observation of temperature and accumulated rainfall}

Figure 8 shows an example of the verification of the retrieved temperature using the corresponding surface measurements at 1100 UTC. Although the density of the surface observations is lower than that of the model's grid points, the surface data still indicate that the temperature distribution varies with the complex topography of southern Taiwan with the temperature being higher near the southwestern coast, decreasing farther inland, and dropping significantly at higher altitudes. These features are well reproduced by IBM_VDRAS, whose analysis field shows a relatively warmer region along the southwestern coast $\left(\sim 22^{\circ} 35^{\prime} \mathrm{N}, 120^{\circ} 20^{\prime} \mathrm{E}\right.$, $)$, and lower temperature near the foothills of the CMR. A quantitative evaluation reveals that the RMSE from the IBM_VDRAS analysis of temperature is $2.35^{\circ} \mathrm{C}$. Note that the current IBM_VDRAS used in this study does not assimilate surface temperature observations, and radars usually cannot provide low-level wind measurements to constrain the model. In addition, the IBM VDRAS retrieved temperature field shown in Fig. 8 is located at a terrain-following surface, which is formed

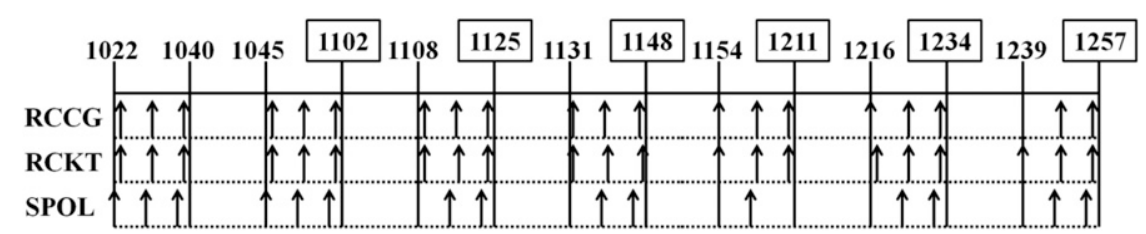

FIG. 6. The radar data assimilation strategy used by IBM_VDRAS. The numbers at the top of the diagram are the starting and finishing times (UTC) of each assimilation cycle. The upward-pointing arrows depict the input radar volume scan data collected by the radars listed on the left (RCCG, RCKT, and SPOL). Six analysis fields generated at the times shown inside the rectangles are utilized in the discussion. 
(a)

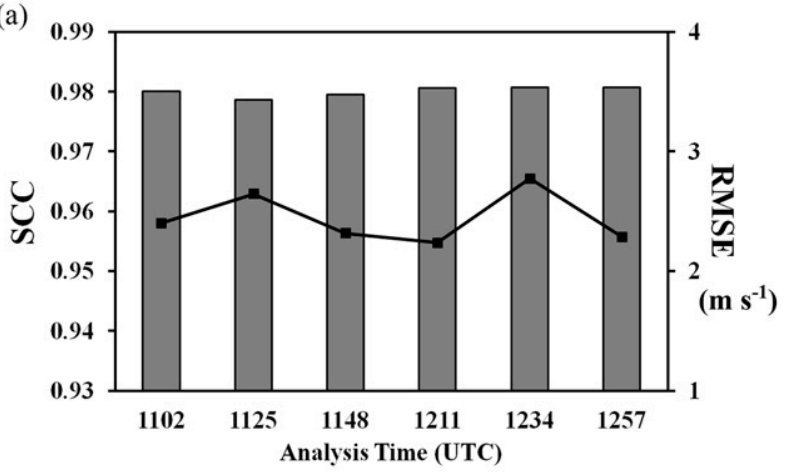

(b)

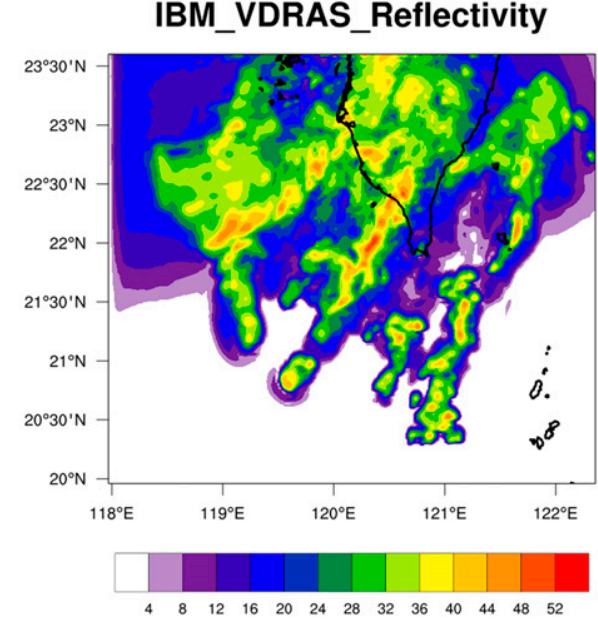

FIG. 7. (a) SCCs (column) and RMSEs (line in $\mathrm{m} \mathrm{s}^{-1}$ ) of IBM_VDRAS analyzed wind at different times compared with the radar radial velocities observed by RCCG; (b) maximum radar reflectivity of each air column generated by IBM_VDRAS at 1234 UTC.

by the first grid point immediately above the terrain at each column. In other words, they are not located at exactly the same altitudes as the surface stations. These factors may contribute to the discrepancy between the IBM_VDRAS retrievals and surface station temperature measurements.

Nevertheless, the SCC which evaluates the degree of similarity of the temperature distribution between the IBM_VDRAS retrievals and the observations shows a value of 0.86 , suggesting a closely matching pattern between these two fields.

In the 2-h accumulated rainfall from 1100 to 1300 UTC produced by IBM_VDRAS (Fig. 9), the main precipitation area is concentrated in the southwestern plain, indicating that with its terrain-resolving capability, IBM_VDRAS is able to reproduce the influence of the CMR on the rainfall distribution. The accumulated amount can reach $35 \mathrm{~mm}$, which is comparable to the observations. Comparison with Fig. 5 shows that the rainfall results produced by IBM_VDRAS are in good

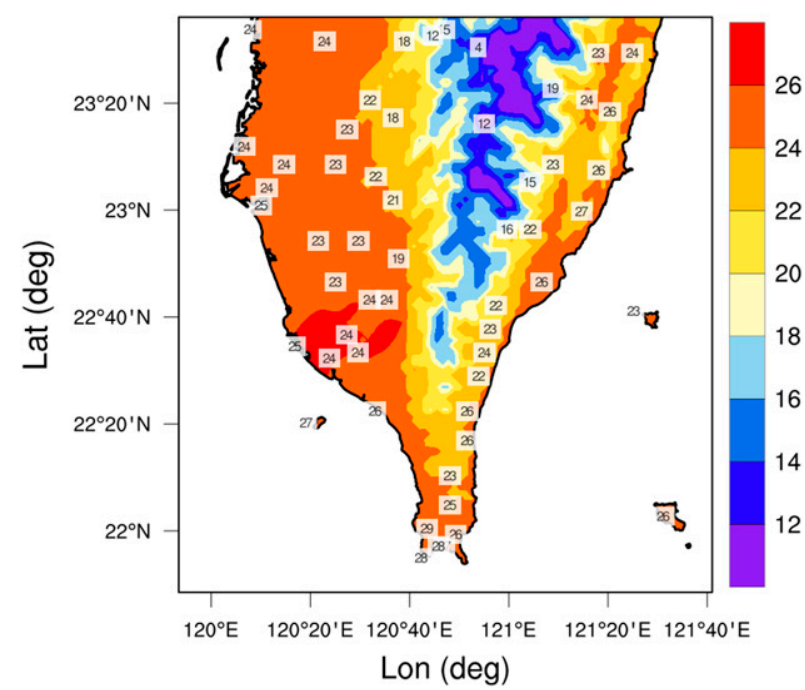

FIG. 8. Surface temperature analysis at 1102 UTC from IBM_VDRAS (shading) and observations by mesonet stations (numbers inside boxes) at 1100 UTC 14 Jun 2008.

agreement with the surface observations, both qualitatively and quantitatively. An additional data assimilation experiment (this experiment is called NT1E, to be introduced in section 8a) was conducted with the CMR removed from the model. It is found that with the presence of the CMR, there is a notable increase $(\sim 10 \mathrm{~mm}$, or approximately $30 \%$ more) in the $2-\mathrm{h}$ accumulated precipitation along the
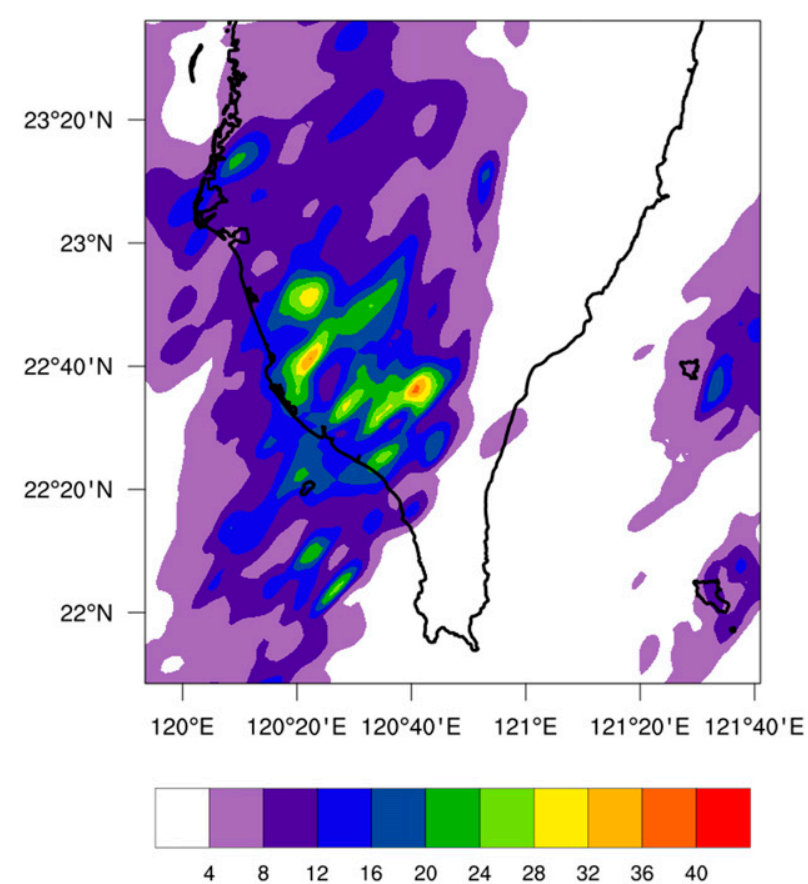

FIG. 9. The $2 \mathrm{~h}$ (from 1100 to $1300 \mathrm{UTC}$ ) of accumulated rainfall $(\mathrm{mm})$ produced by IBM_VDRAS. 
(a)

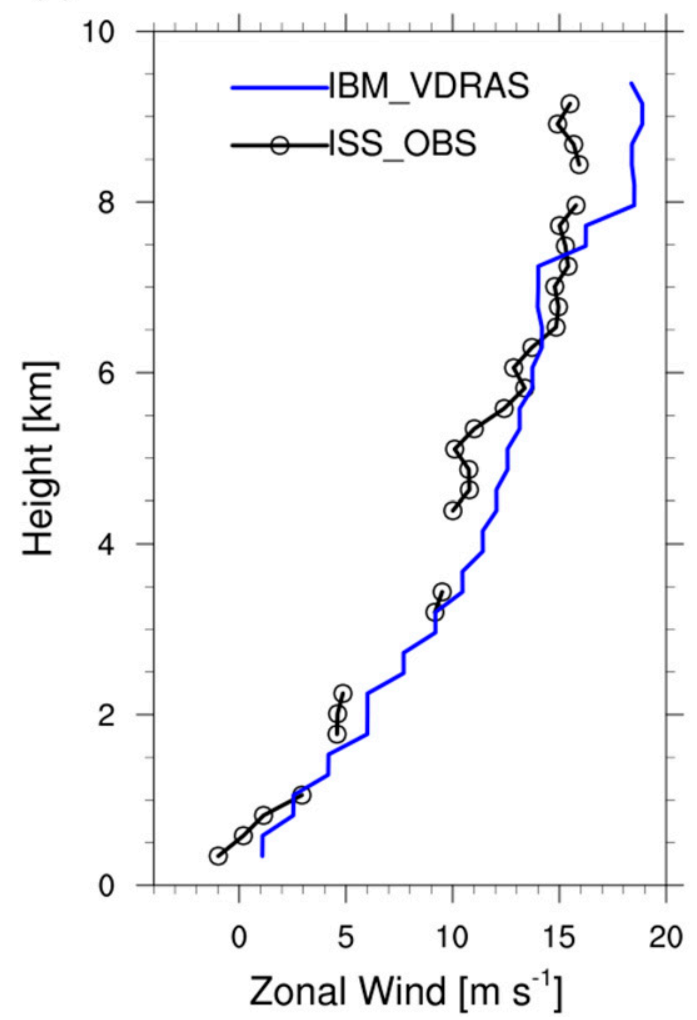

(b)

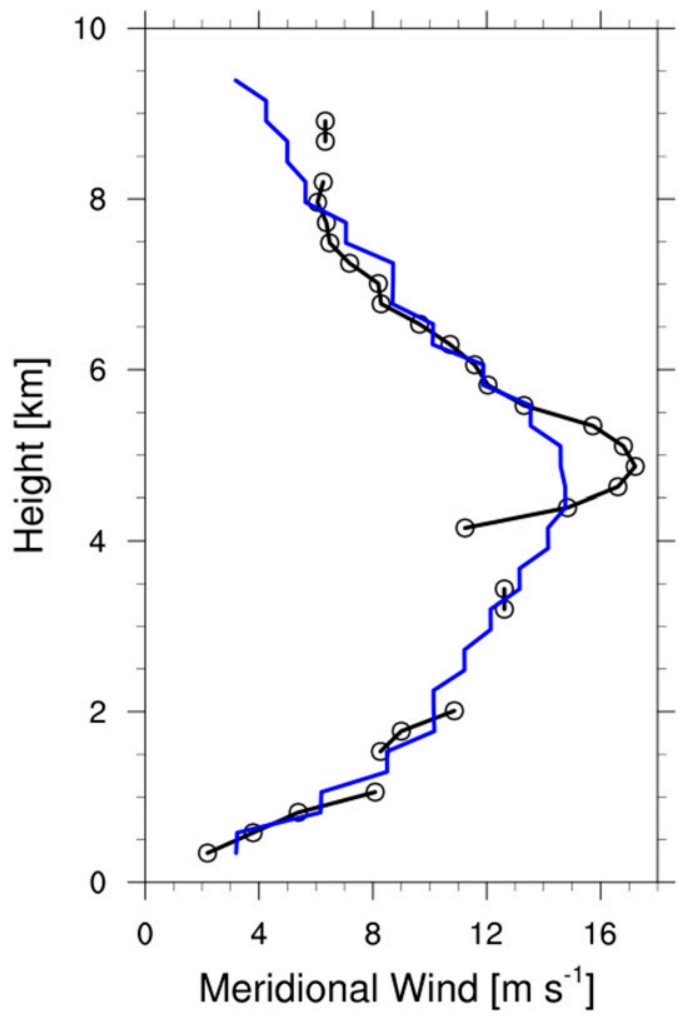

FIG. 10. Wind profiles produced by IBM_VDRAS at 1102 UTC (blue solid line) and observed by the ISS profiler at 1115 UTC 14 Jun 2008 (circles connected by solid black line): (a),(b) $u$ and $v$ components ( $\mathrm{m} \mathrm{s}^{-1}$ ), respectively.

slope of the CMR, while over the southwestern plain there is significant spatial variation in the difference in precipitation (not shown). This difference demonstrates that the increase of rainfall was related to the enhanced ascent and associated condensation on the windward side due to the presence of the terrain.

\section{c. 915-MHz Integrated Sounding System (ISS) wind profiler}

An ISS wind profiler was deployed near the foothills of the southern branch of the CMR (see Fig. 2). Its observations representing the terrain-influenced winds were used as a reference for validation of our analyses. The profiler data observed at 1115 UTC were selected because contamination of the data by rainfall was not significant at this time. Centered on the ISS profiler data points, the inverse distance weighting (IDW) method is applied for spatial interpolation of the IBM_VDRAS results. The search distance consists of three grid points in each direction. The vertical profiles of the model wind fields produced through this procedure are compared with the ISS observations.

Figure 10 demonstrates an example at 1102 UTC, the time closest to the ISS observation. The results of
IBM_VDRAS wind analysis agree very well with the profiler measurements from the surface to $10 \mathrm{~km}$ in height. The RMSE and SCC between the IBM_VDRAS results and the profiler measurements are $1.74 \mathrm{~m} \mathrm{~s}^{-1}$ and 0.97 for the $u$ component of the wind, and $1.27 \mathrm{~m} \mathrm{~s}^{-1}$ and 0.94 for the $v$ component of the wind, respectively, indicating a high consistency with the ISS observation.

\section{d. Radiosonde}

For the purpose of independent validation, data collected by the Pingtung radiosonde station (location shown in Fig. 2) at 1200 UTC are not included in the mesoscale background field. The IBM_VDRAS analyses generated at 1211 UTC are selected for comparison. Note that the IBM_VDRAS analysis fields are also interpolated to the location of the Pingtung sounding site by using the IDW method.

As shown in Figs. 11a and 11b, the IBM_VDRAS performs well for temperature and pressure retrievals. The retrieved profiles of horizontal winds, although smoother, still exhibit a vertical distribution and magnitude consistent with the sounding measurements (Figs. 11c,d). The RMSE and SCC between the winds 
(a)

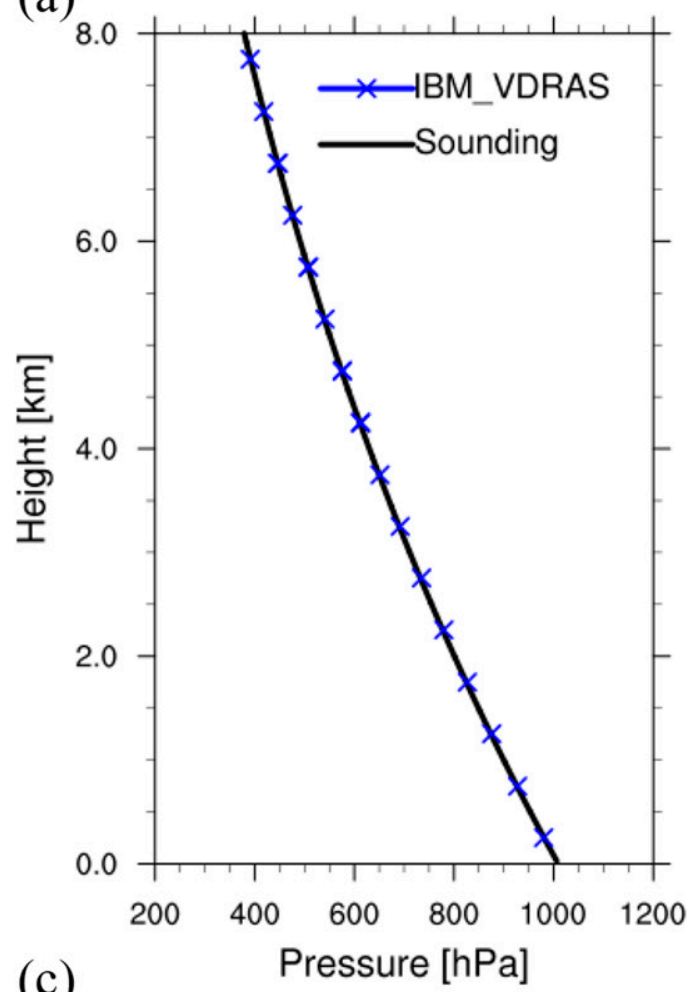

(c)

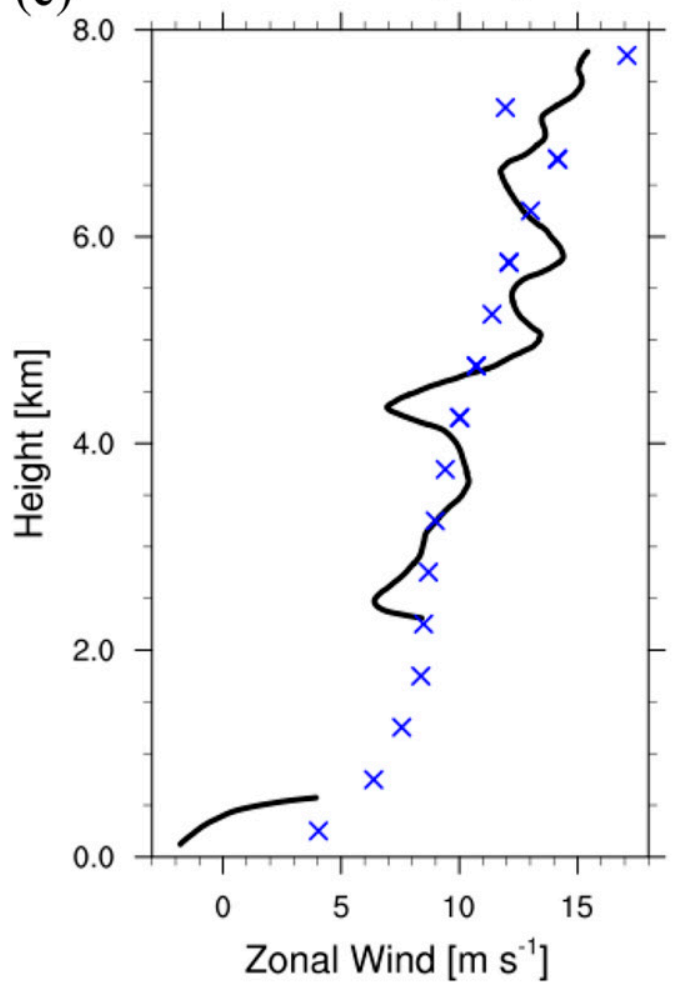

(b)

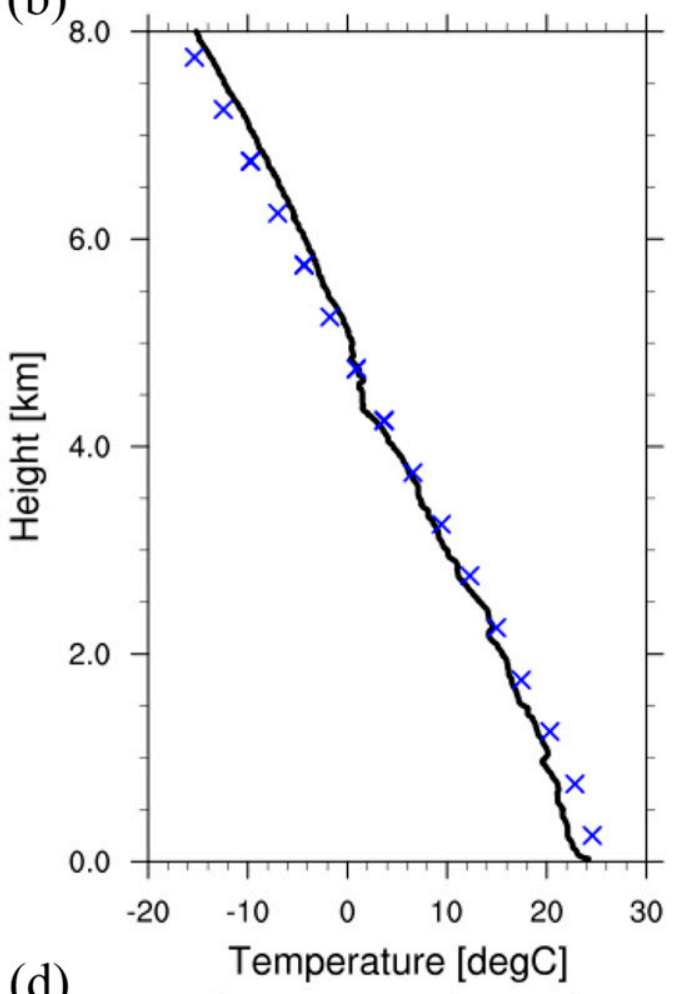

(d)

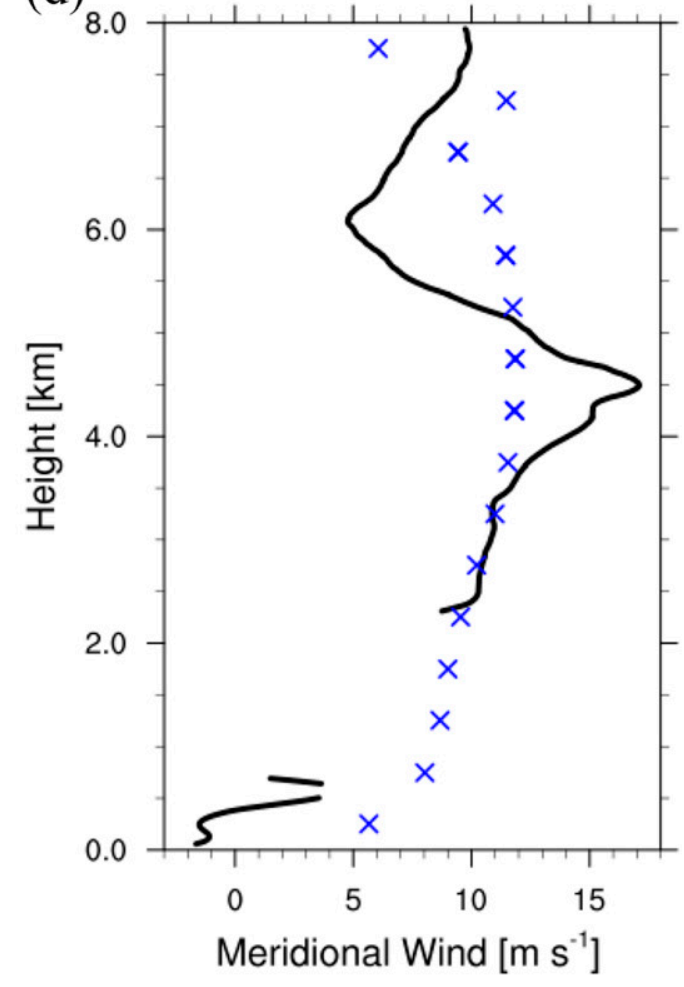

FIG. 11. Profiles of variables produced by IBM_VDRAS analysis at 1211 UTC (blue crosses) and observed by the radiosonde (black solid line) launched from the Pingtung station at 1200 UTC 14 Jun 2008: (a)-(d) the results for pressure $(\mathrm{hPa})$, temperature $\left({ }^{\circ} \mathrm{C}\right)$, and zonal and meridional wind $\left(\mathrm{m} \mathrm{s}^{-1}\right)$, respectively. 
retrieved by IBM_VDRAS and the radiosonde measurements are $1.99 \mathrm{~m} \mathrm{~s}^{-1}$ and 0.87 for the $u$ component of the wind, and $3.57 \mathrm{~m} \mathrm{~s}^{-1}$ and 0.61 for the $v$ component of the wind, respectively. The relatively higher discrepancy than that obtained with the ISS profiler data may be attributed to the horizontal drift of the radiosonde during ascension process. As for the thermodynamic fields, the RMSE for the temperature and pressure are $1.3^{\circ} \mathrm{C}$ and $1.54 \mathrm{hPa}$, respectively, while the SCC for both variables can reach 0.9 .

\section{Structure of the rainfall system revealed by the multivariate analyses}

The major structures in the prefrontal rainbands are investigated using the high spatiotemporal resolution three-dimensional analysis fields generated by IBM_VDRAS.

\section{a. Analysis over the terrain-following surface}

Figure 12 shows the wind vectors, horizontal convergence, and rainwater mixing ratios at different analysis times over a terrain-following surface (see the definition in section 6b). Note the three line-shaped regions with high rainwater mixing ratios collocated with the rainbands depicted in Fig. 4. The prevailing southwesterly flow is deflected as it approaches the coast. The winds become more southerly over land. Further computation of the wind speed reveals that substantial deceleration takes place in the southwestern plain area (not shown). Observe that the rainbands move in a direction that is almost perpendicular to the southwesterly flow, which implies that it is large-scale forcing rather than a local effect that is driving their movement. The rainfall data collected by rain gauges also indicate that rainfall has spread out over southwestern part of Taiwan. The region with high concentration of precipitation basically follows the movement of the rainband $\mathrm{B}$, as depicted in Fig. 5.

Convergence lines associated with the moving rainbands A and B (see Fig. 4 for their locations) can be recognized. Figure 12 reveals a persistent convergent zone along the southwest coast of Taiwan. Davis and Lee (2012) found a similar phenomenon, and mentioned the difficulty in defining the spatial scale of the "coastal front boundary" owing to observational limitations. However, by assimilating the radar data into IBM_ VDRAS, the convergent structure is well reproduced in the current study.

Evidence of the coastal convergence can also be found from mesonet measurements of the surface wind. As illustrated in Fig. 13, the surface wind vectors observed at 1100,1200 , and 1300 UTC reveal the presence of an offshore flow over the southwestern plain. This is also confirmed by the data collected by a radiosonde released at 1200 UTC, which indicates the existence of an offshore wind below $0.4 \mathrm{~km}$ (see Fig. 16b). As the prevailing wind from the ocean is dominated by a southwesterly flow, low-level convergence is expected to occur near the coastal regions.

\section{b. Topographic effect revealed by averaged (along $y$ axis) characteristics in an $x-z$ cross section and the maintenance of the rainfall system}

To highlight the influence of the terrain on the flow, the atmospheric states averaged along the $y$ axis are displayed in an $x-z$ vertical cross section covering a latitude range from $22.5^{\circ}$ to $23.6^{\circ} \mathrm{N}$, which includes most of the terrain-influenced region around the southern part of the CMR. The analysis results at 1234 UTC are selected as an example for discussion, since the overall features do not change much with time. Figure 14a shows substantial deceleration in the $u$ component of the wind from the coastal area $\left(\sim 120^{\circ} \mathrm{E}\right)$ to the foothills of the CMR. A westerly wind exists at the upper layers $(Z \sim 8.0 \mathrm{~km})$, with the wind speed increasing toward the east, leading to a region of divergence at that altitude. In addition, the pressure perturbation increases as one approaches from the west toward the CMR (Fig. 14b), forming a horizontal pressure gradient force oriented toward the ocean. The vertical motion is plotted in Fig. 14c. Note that upward motion was present near the coastal area $\left(\sim 120.0^{\circ} \mathrm{E}\right)$ and approximately $50 \mathrm{~km}$ inland, collocated with the deceleration of the horizontal wind speed (see Fig. 14a). The maximum updraft is found at $Z \sim 5.5 \mathrm{~km}$. Downward motion can be identified along the upslope of the CMR, and above the mountain peaks. As seen in Fig. 14d, rainwater is mostly generated near the foothills and along the upslope of the CMR. Reduction of rainwater is found on the leeside of the CMR.

According to the aforementioned analyses, the persistent convergence zone near the southwestern coast supports the growth and enhancement of the convection. The mechanism causing this coastal convergence can be attributed to onshore (northeastward) and offshore (southwestward) flows. Note that the latter existed below a very shallow depth $(<0.4 \mathrm{~km})$, and was identified only in observations by surface stations. The onshore wind derives from the prevailing southwesterly flow with temporal variations in intensity, but is decelerated by surface friction and topographic blockage after making landfall. Convective cells lifted by the coastal convergence then develop at higher altitudes. The precipitation hydrometeors are advected inland by the southwesterly or southerly flow, to be blocked by the 
(a) 1102 UTC

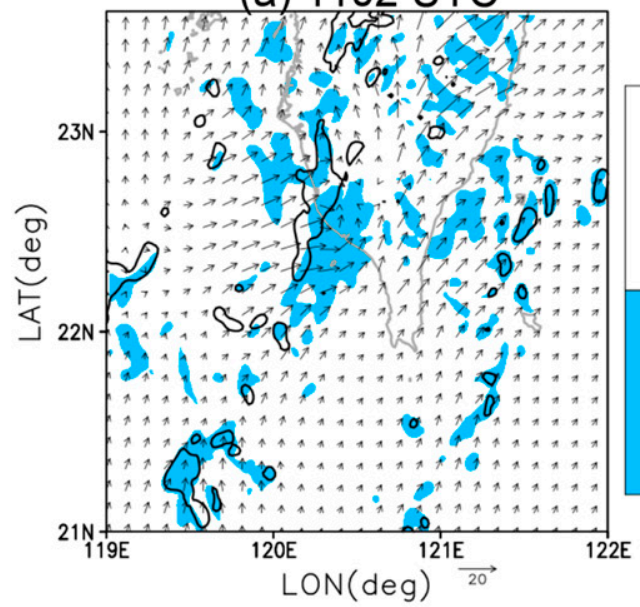

(b) 1125 UTC

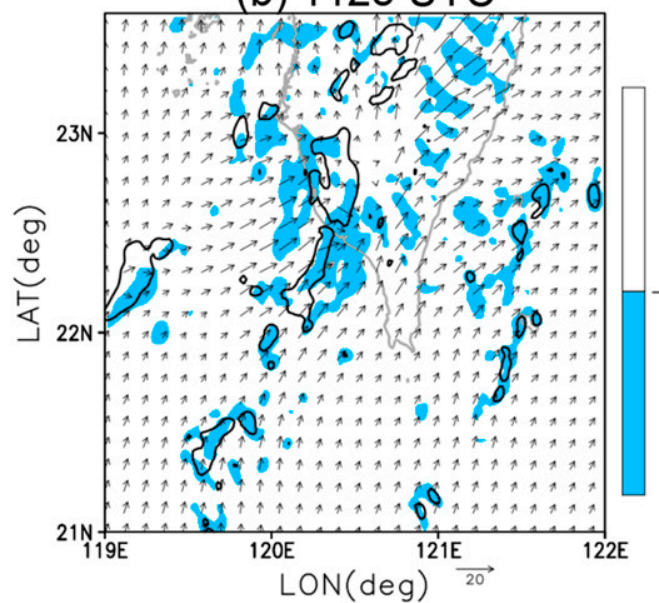

(c) 1148 UTC

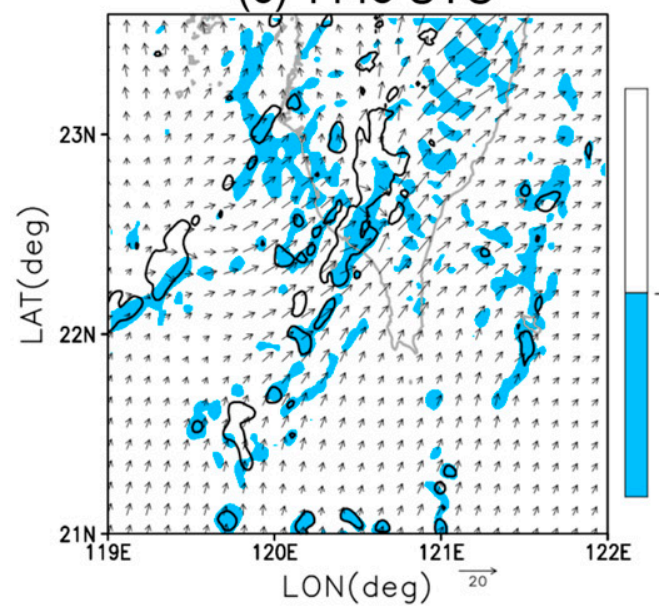

(d) 1211 UTC

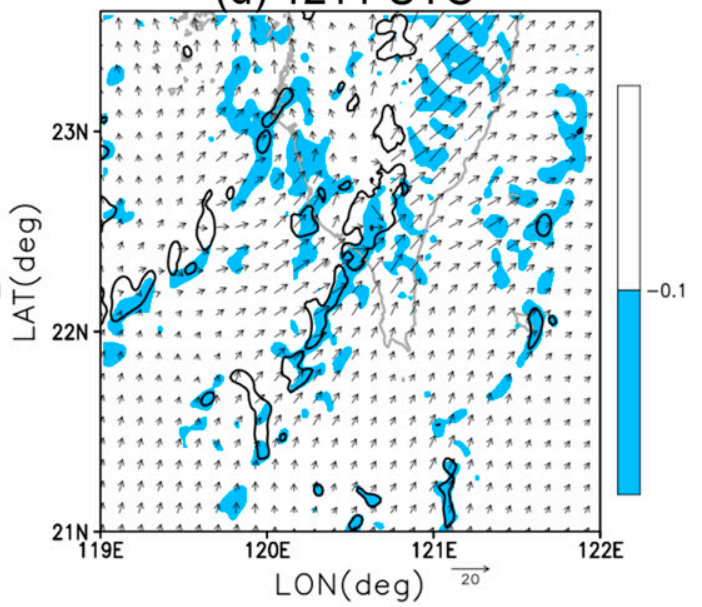

(e) 1234 UTC

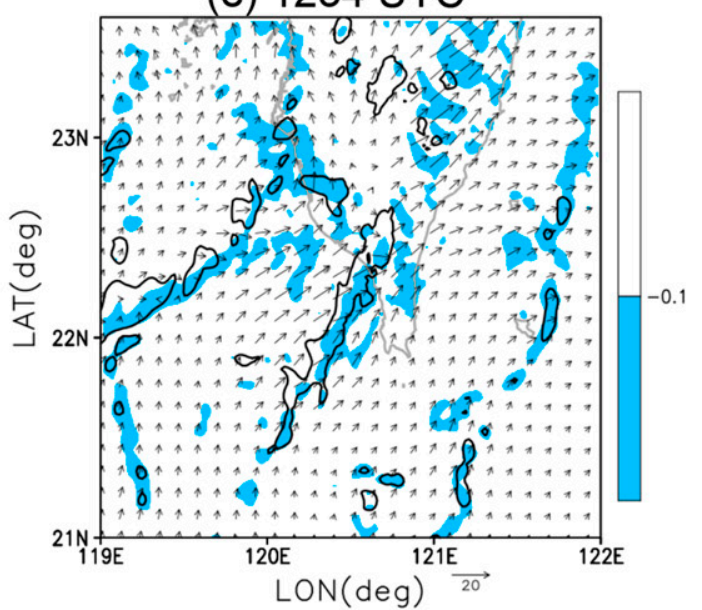

(f) 1257 UTC

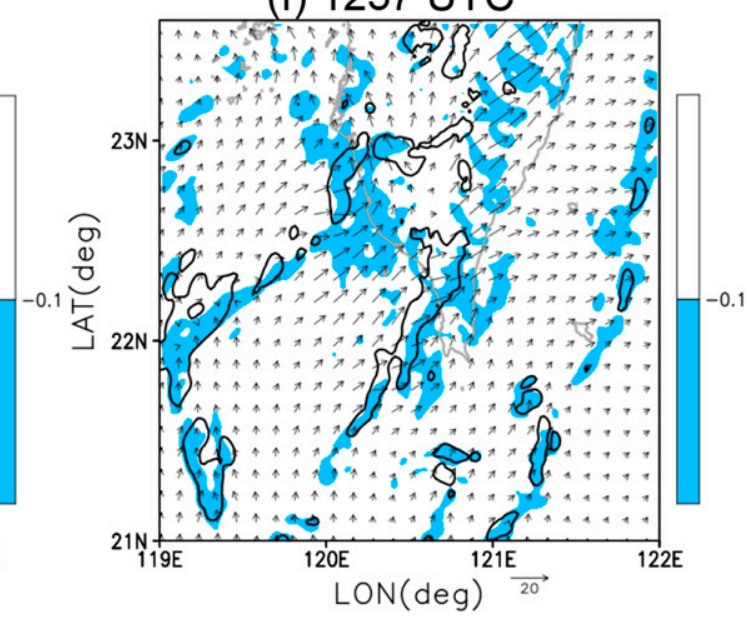

FIG. 12. IBM_VDRAS analyses over the terrain-following surface. The blue shading represents horizontal convergence greater than $-0.1\left(\times 10^{-3} \mathrm{~s}^{-1}\right)$. Contour lines depict rainwater mixing ratio $\left(\mathrm{g} \mathrm{kg}^{-1}\right)$ greater than $0.4 \mathrm{~g} \mathrm{~kg}^{-1}$. Vectors are plotted to show horizontal wind. Six analyses are displayed at (a) 1102, (b) 1125, (c) 1148, (d) 1211 , (e) 1234, and (f) 1257 UTC, respectively. 
(a) 1100 UTC

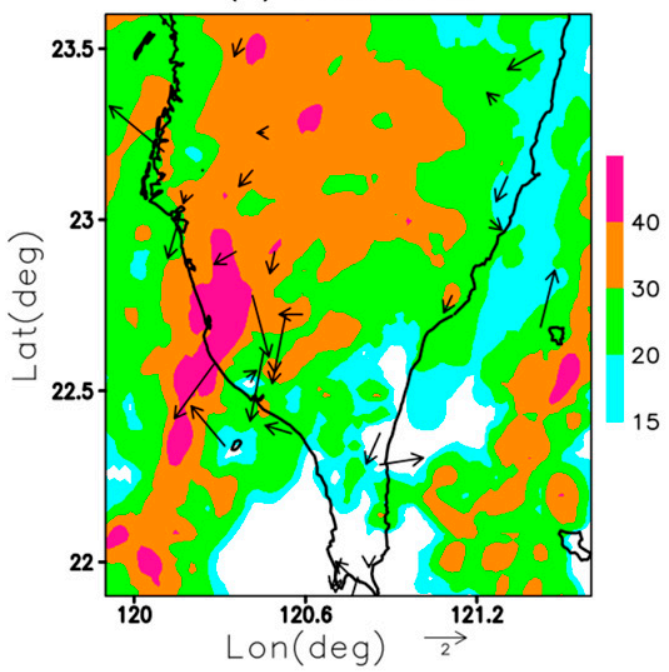

(b) 1200 UTC

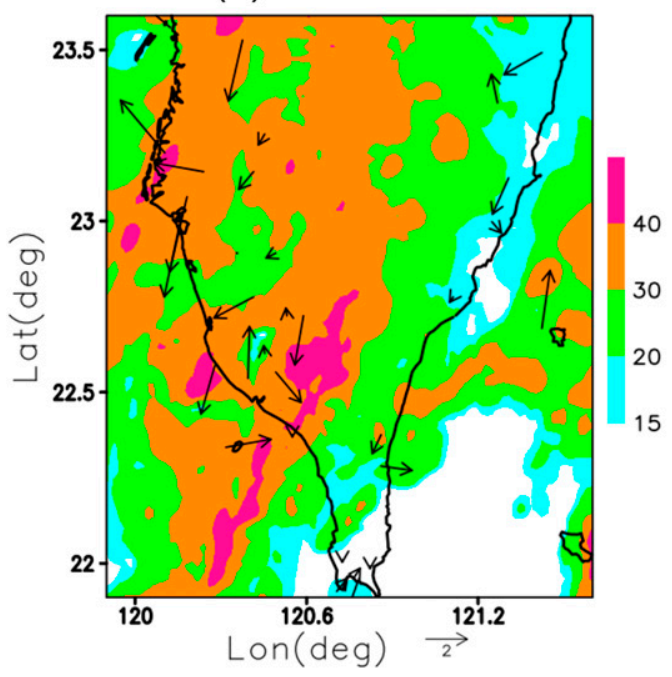

CMR, leading to the occurrence of rainfall on the windward side of the CMR. The cooling effect associated with the precipitation near the CMR produces a spatial temperature distribution with relatively colder (denser) and warmer (lighter) air near the foothills of the CMR and along the coast, respectively. This temperature difference can be revealed by the IBM VDRAS retrievals and surface station observations, as illustrated in Fig. 8. The air density difference induces a pressure gradient force (see Fig. 14b) pointing toward the ocean, leading to an offshore wind component near the surface (see Fig. 13).

The major features retrieved by IBM_VDRAS as described above are partially supported by radiosonde observations released from a ship and the Pingtung station (see Fig. 2 for their locations).

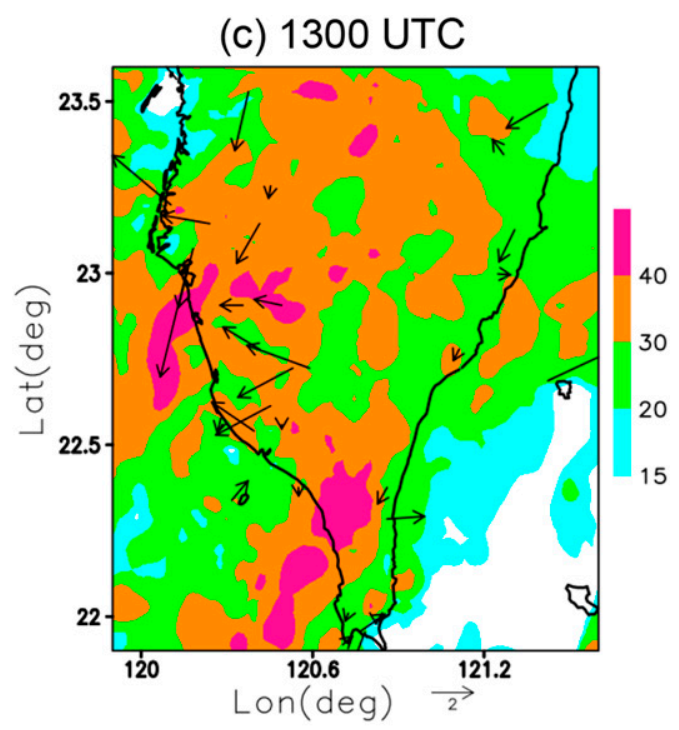

FIG. 13. Surface wind vector observations $\left(\mathrm{m} \mathrm{s}^{-1}\right)$ recorded by mesonet stations at altitudes below $0.2 \mathrm{~km}$ and maximum radar reflectivity of each air column (color shading in $\mathrm{dBZ}$ ) on $14 \mathrm{Jun}$ 2008: (a)-(c) at 1100, 1200, and 1300 UTC, respectively.
These observations represent the weather conditions on the upstream ocean and southwestern plain near the mountains, respectively. A comparison of the temperature and pressure profiles at low levels indicates the existence of a notable temperature gradient below $Z=1 \mathrm{~km}$ (Fig. 15a) with the atmosphere over the land being approximately $2^{\circ} \mathrm{C}$ colder than that over the ocean. Furthermore, as can be seen in Fig. 15b, the pressure is higher near the mountains than that measured over the upstream ocean. In addition, the wind speed deceleration is also prominent at lower altitudes as can be observed by comparing the wind measurements obtained over ocean and land (Fig. 16a). Note that a very shallow layer of offshore wind component is detected below $Z=0.4 \mathrm{~km}$ (see Fig. 16b). In general, the radiosonde measurements 
(a) Zonal Wind $\left(\mathrm{m} \mathrm{s}^{-1}\right)$

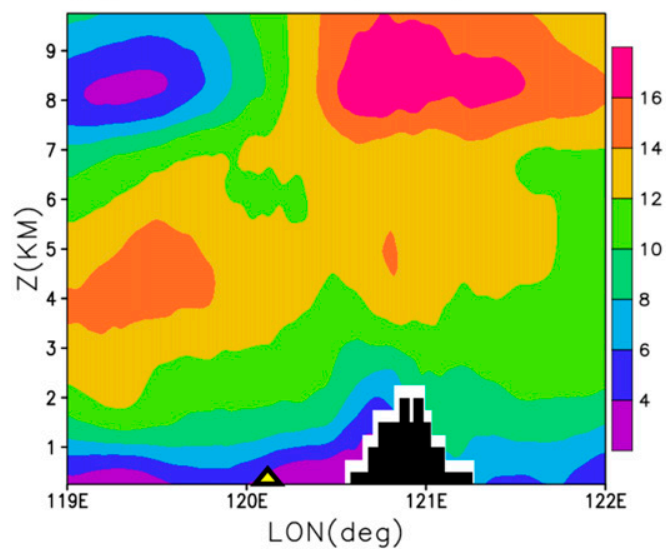

(b) $\mathrm{P}$ pert. $(\mathrm{hPa})$

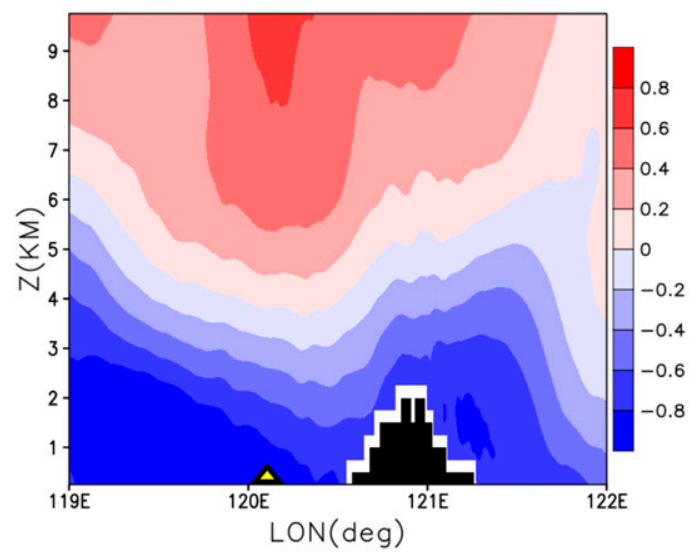

(c) Vertical velocity $\left(\mathrm{m} \mathrm{s}^{-1}\right)$

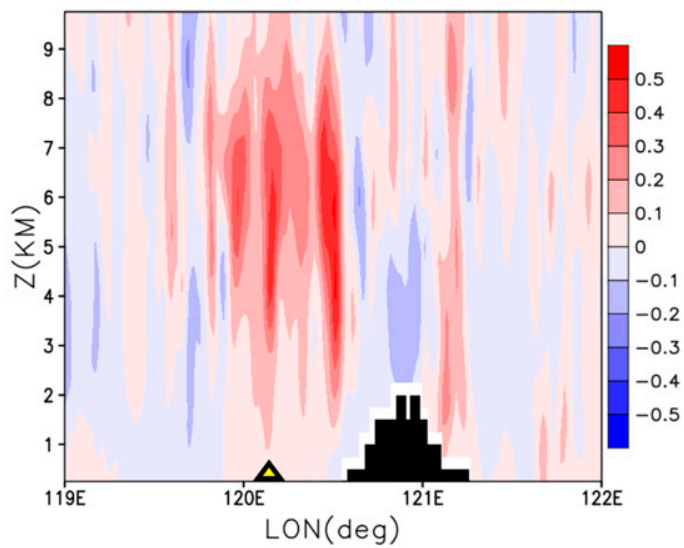

(d) Rainwater mixing ratio $\left(\mathrm{g} \mathrm{kg}^{-1}\right)$

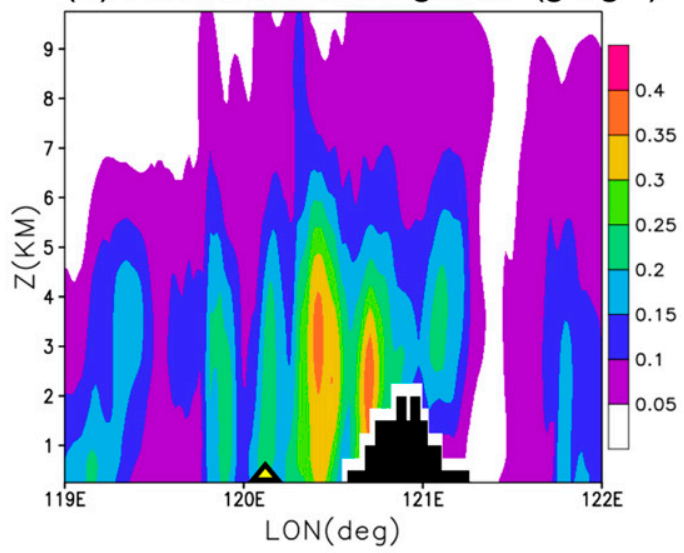

FIG. 14. Averaged fields along the $y$-axis direction at 1234 UTC for (a) zonal wind $\left(\mathrm{m} \mathrm{s}^{-1}\right)$, (b) pressure perturbation $(\mathrm{hPa}),(\mathrm{c})$ vertical velocity $\left(\mathrm{m} \mathrm{s}^{-1}\right)$, and (d) rainwater mixing ratio $\left(\mathrm{g} \mathrm{kg}^{-1}\right)$. The small triangle in the $x$ axis indicates the location of the coastline.

support the findings obtained by analyzing the IBM VDRAS results.

\section{Diagnosis of the precipitation mechanisms}

In previous sections, it has been shown that the lowlevel convergence flow associated with the deceleration and shallow offshore wind induced by factors such as topographic blockage and cold air outflow over the southwestern plain of Taiwan plays an important role in the enhancement and maintenance of precipitating cells in the rainbands. In this section the relative importance of the cooling and topographic effects is diagnosed quantitatively through a series of sensitivity experiments.

\section{a. Design of sensitivity experiments}

To understand the impact of the evaporation process and/or topographic effects, a series of experiments are designed and listed in Table 1. Our approach is to let the cloud model used in IBM_VDRAS be constrained by the same sets of observational data and assimilation strategy, while the terrain and/or evaporation are chosen to be present or not in the model. Thus, the experiments include a control experiment "YT1E," which is the same as that discussed in section 5, with the complex terrain and evaporation process implemented in the forward and adjoint models. In "NT0E" both the topography and evaporation processes are removed. In "YTOE," the topography is included, but the evaporation process is turned off. In contrast, in "NT1E" there is no terrain in the domain, but the evaporation process is included in the computation. Finally, in "YT10E," the evaporation effect is amplified 10 times, to highlight its influence on the results retrieved by IBM_VDRAS after 4DVar data assimilation.

As illustrated in Fig. 17, by computing the differences between each experiment, it is possible to identify the 
(a)
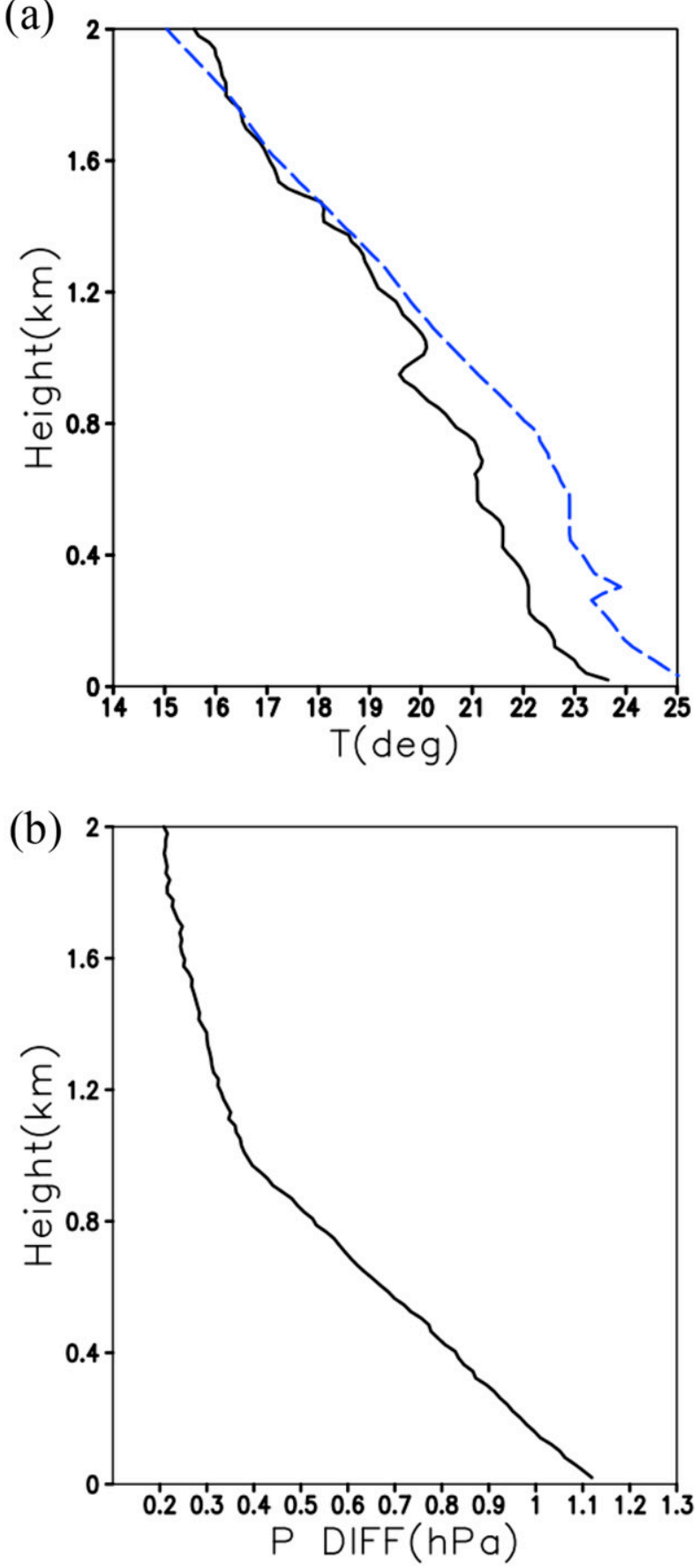

FIG. 15. Observed vertical profiles at 1200 UTC 14 Jun 2008 from surface to $2.0 \mathrm{~km}$ height for $(\mathrm{a})$ temperature $\left({ }^{\circ} \mathrm{C}\right)$ from the radiosonde launched at Pingtung (black solid line) and the ship (blue dashed line), and (b) pressure difference (hPa) obtained by subtracting the ship observation from Pingtung observation.

impact of different mechanisms, namely, terrain blockage, evaporation, and a combination of both. A list of these mechanisms and interpretation can be found in Table 2 . Since the existing VDRAS lacks the terrain-resolving capability, which is equivalent to the NT1E experiment in this study, the results produced by experiment NT1E can be used to demonstrate the differences between IBM_VDRAS and the existing VDRAS.

By subtracting NT0E from YT1E, we obtain TEREVP which represents the differences after the effects of both terrain and evaporation are removed from the model:

$$
\text { YT1E }- \text { NT0E }=\text { TEREVP } .
$$

With the presence of the evaporation process, TER estimates the influence of the terrain by computing the difference between YT1E and NT1E:

$$
\mathrm{YT} 1 \mathrm{E}-\mathrm{NT} 1 \mathrm{E}=\mathrm{TER} .
$$

When terrain exists in the domain, but the evaporation process is turned off (YT0E) or on (YT1E), the difference is named EVP,

$$
\text { YT1E }- \text { YT0E }=\text { EVP } .
$$

Without evaporation, the pure topographic effect (PTER) is revealed by removing NT0E from YT0E as follows:

$$
\text { YTOE }- \text { NTOE }=\text { PTER } .
$$

Similarly, one can isolate the pure evaporation effect (PEVP) without terrain by subtracting NTOE from NT1E as follows:

$$
\text { NT1E }- \text { NT0E }=\text { PEVP. }
$$

From Fig. 17 and (2)-(6), it can also be seen that the total effect (TEREVP) is equal to the sum of PTER and EVP, or PEVP and TER, as shown below,

$$
\text { TEREVP }=\text { EVP }+ \text { PTER }=\text { TER }+ \text { PEVP }
$$

It is interesting to find that a new term, called INT in this derivation, can be extracted by computing the differences between either TER and PTER, or EVP and PEVP as follows:

$$
\begin{aligned}
& (\mathrm{YT} 1 \mathrm{E}-\mathrm{NT1E})-(\mathrm{YT0E}-\mathrm{NT0E}) \\
& =(\mathrm{YT1E}-\mathrm{YT0E})-(\mathrm{NT1E}-\mathrm{NT0E}) \\
& =\text { TER }- \text { PTER }=\text { EVP }- \text { PEVP }=\text { INT } .
\end{aligned}
$$

This INT term can be interpreted as a nonlinear interactive effect between terrain and evaporation.

Finally, from (7) and (8), TEREVP can be expressed by

$$
\text { TEREVP }=\text { PTER }+ \text { PEVP }+ \text { INT } .
$$




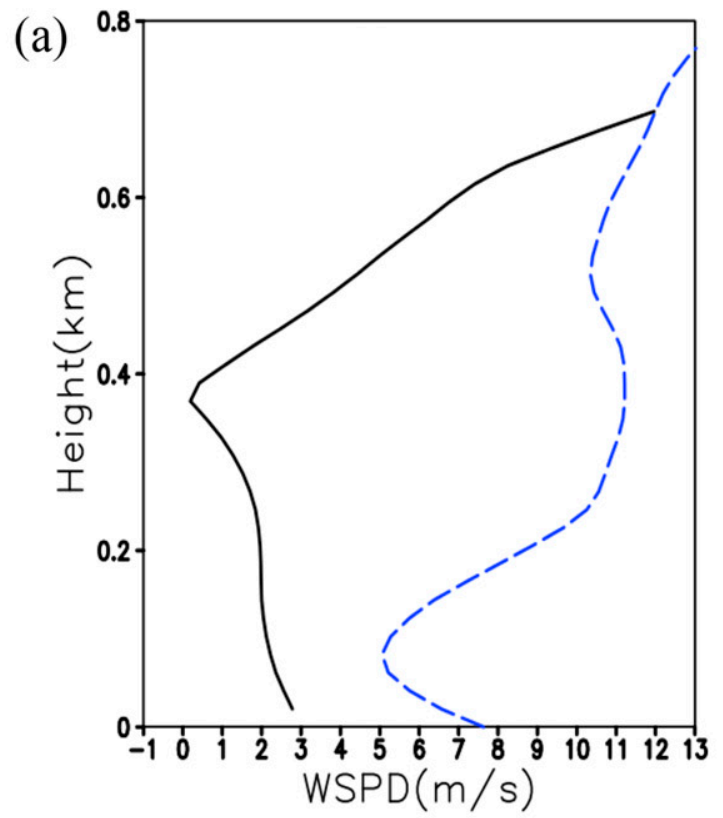

(b)

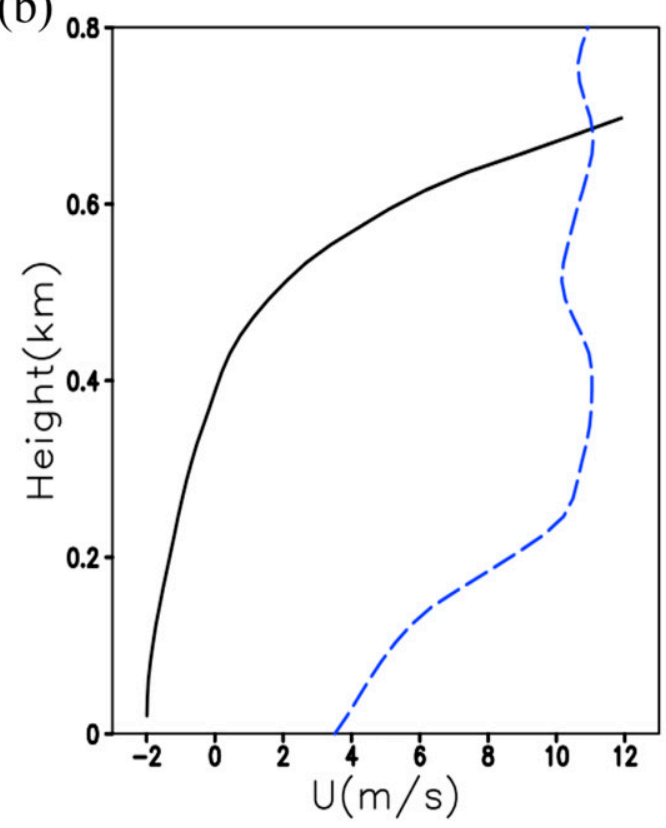

(c)

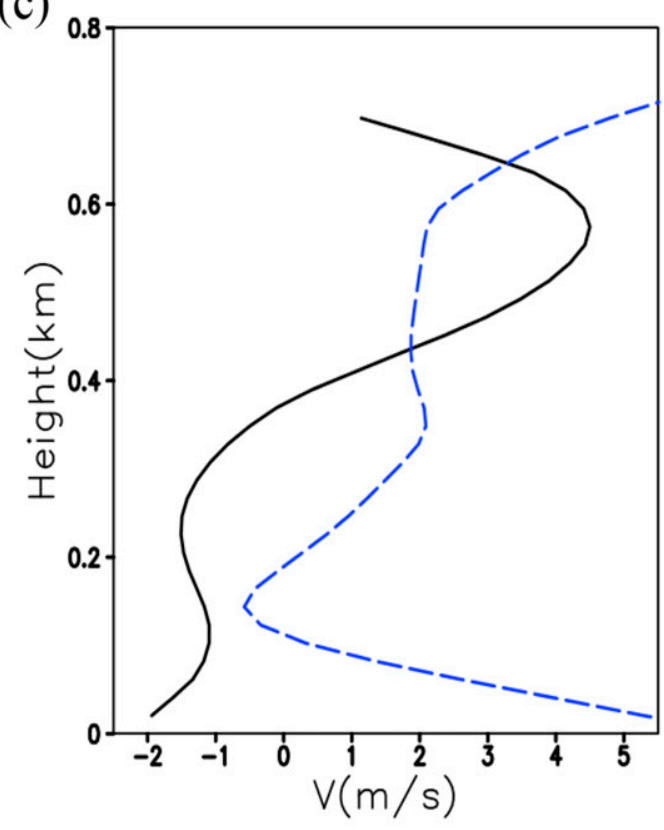

FIG. 16. Observed vertical profiles at 1200 UTC 14 Jun 2008 from surface to $0.8 \mathrm{~km}$ height from a radiosonde launched at Pingtung (black line) and the ship (blue dashed line). (a)-(c) The results for the wind speed, and the $u$ and $v$ components of the wind $\left(\mathrm{m} \mathrm{s}^{-1}\right)$, respectively.

Equation (9) suggests that the total effect (TEREVP) can be decomposed into three components: pure terrain (PTER), pure evaporation (PEVP), and the nonlinear interaction between terrain and evaporation (INT). On this basis, the individual effect of each component can be compared and discussed in a quantitative sense. Note that since similar results are found at different analysis times, only the differences calculated at 1234 UTC are discussed in detail.

\section{b. Differences over the terrain-following surface}

The effects induced by topography and/or evaporation are examined by showing the differences along the terrain-following layer. Note that for a fair comparison, the exact same grids are selected for point-to-point 
TABLE 1. List of all sensitivity experiments.

\begin{tabular}{lcc}
\hline & Topography & Amplification of evaporation \\
\hline NT0E & No & 0 \\
NT1E & No & 1 \\
YT0E & Yes & 0 \\
YT1E & Yes & 1 \\
YT10E & Yes & 10 \\
\hline
\end{tabular}

subtraction between two fields for all experiments, including NT0E and NT1E, in which the terrain is removed.

Comparison of the $u$ component of the wind for TEREVP (Fig. 18a) shows a prominent deceleration (acceleration) along the slope of the windward (lee) side of the CMR when the terrain and evaporation are both present. A small region of acceleration surrounded by deceleration is identified over the southwestern plain $\left(\sim 23.0^{\circ} \mathrm{N}, 120.4^{\circ} \mathrm{E}\right)$. Also, an area of acceleration is found at the southern tip of Taiwan, which extends southwestward to the ocean. As indicated in Fig. 18b, the pure orographic effect expressed by PTER closely resembles that obtained with TEREVP. Wind deceleration and acceleration along the windward (west) and leeside (east) of the CMR, respectively, are found when the CMR is present. By contrast, the evaporation process depicted by PEVP generates much smaller differences (Fig. 18c), with only a slight deceleration over the southwestern plain area of Taiwan. On the other hand, the contribution from the nonlinear interaction between the topography and evaporation process (INT), as displayed in Fig. 18d, turns out to be stronger than for PEVP. Deceleration induced by INT is present to the west of the CMR. In addition, there is a region $\left(\sim 22.25^{\circ} \mathrm{N}, 120.25^{\circ} \mathrm{E}\right)$ with a notable amount of deceleration stretching southwestward from the coast to the ocean, which compensates for the acceleration generated by PTER in the same region (Fig. 18b). These results suggest that the contribution from the topographic effect alone dominates the performance of the total effect, while the contribution from nonlinear interaction plays a secondary but nonnegligible role in terms of modifying the flow fields. Similar features are found in the differences of the $v$ component of the wind (not shown), indicating that the topographic effect is the principal factor in controlling the wind structure.

The temperature and pressure differences illustrated in Figs. 18e-h and 18i-l, respectively, reveal that the total effect (TEREVP) generally enhances cooling (warming) on the windward (lee) side of the CMR (Fig. 18e), triggering the development of higher (lower) pressure (Fig. 18i). An area of intensified warming is located over the southwestern plain $\left(\sim 23.0^{\circ} \mathrm{N}, 120.5^{\circ} \mathrm{E}\right)$.

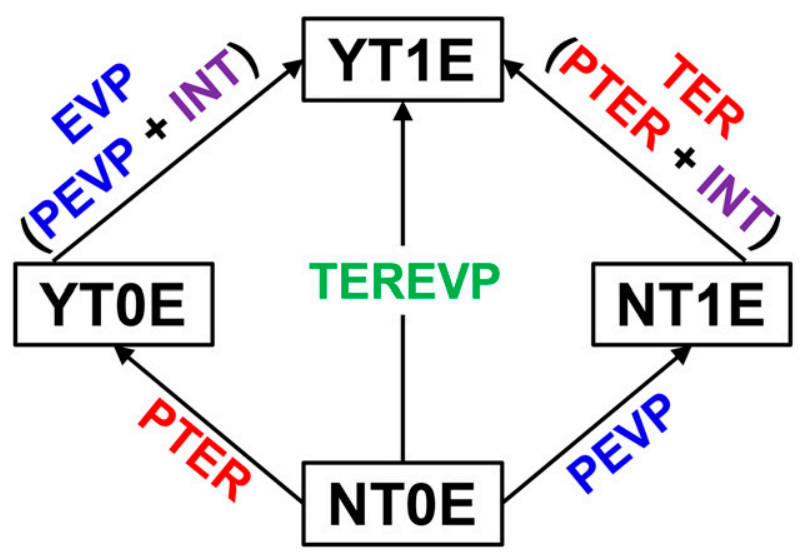

FIG. 17. The relationships among sensitivity experiments (shown in the rectangle). Definition and interpretation of the differences between two selected experiments are explained in the text.

A purely topographic effect (PTER) tends to produce warmer air and lower pressure on the western side of the CMR (Figs. 18f,j), but these are substantially compensated for by INT (Figs. 18h,1). Given the relatively minor differences due to the pure evaporation process in PEVP (Figs. 18g,k), these figures indicate that the cooling effect is primarily produced through the nonlinear interactive effect INT. The presence of the CMR helps to maintain precipitation over the windward side of the mountains, showing that the topography can strengthen the rain-evaporative cooling effect in an indirect manner.

The distribution of the differences in the 2-h (from 1100 to 1300 UTC) accumulated rainfall are plotted in Figs. $18 \mathrm{~m}-$ p. The overall distribution of the difference in rainfall indicates that the presence of the terrain and evaporation tend to produce an increase along the western slope of the CMR, and a reduction over the southwestern plain area. Further analysis shows that the increase is mainly induced by the pure terrain effect (PTER), and it is the nonlinear interaction term (INT) that leads to the

TABLE 2. List of the rainfall mechanisms identified in this study.

\begin{tabular}{ll}
\hline \hline Mechanism & \multicolumn{1}{c}{ Interpretation } \\
\hline TEREVP & $\begin{array}{c}\text { Total effect with the presence of terrain } \\
\text { and evaporation } \\
\text { Topographic effect with the presence of } \\
\text { evaporation } \\
\text { Evaporative effect with the presence of } \\
\text { terrain }\end{array}$ \\
EVP & $\begin{array}{l}\text { Pure topographic effect without } \\
\text { evaporation } \\
\text { PTER }\end{array}$ \\
PEVP & $\begin{array}{l}\text { Pure evaporative effect without terrain } \\
\text { terrain and evaporation }\end{array}$ \\
INT &
\end{tabular}




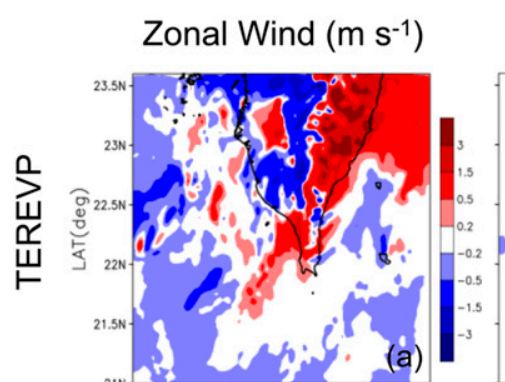

Temperature $\left({ }^{\circ} \mathrm{C}\right)$

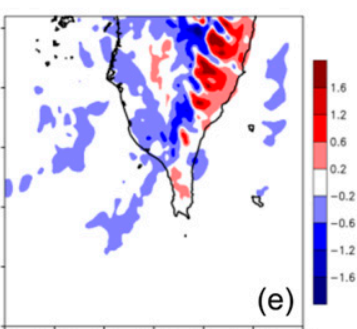

(e)

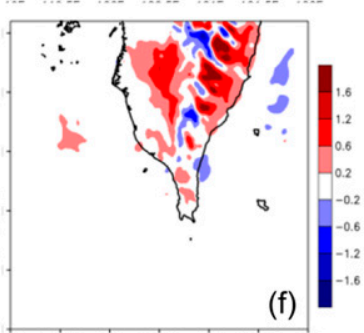

(f)
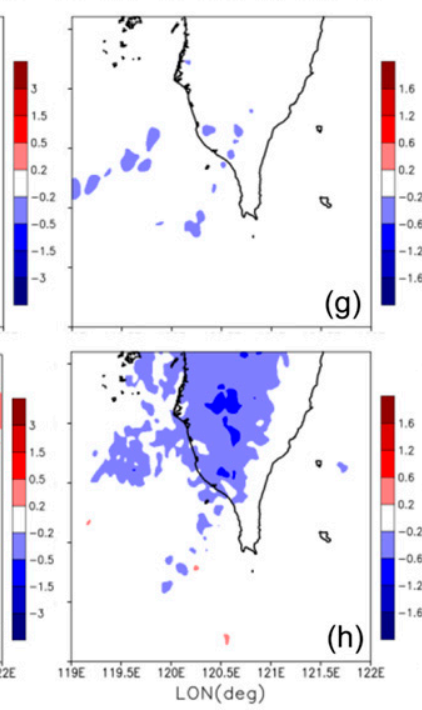

Pressure (hPa)

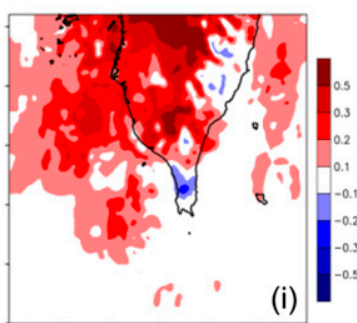

(i)

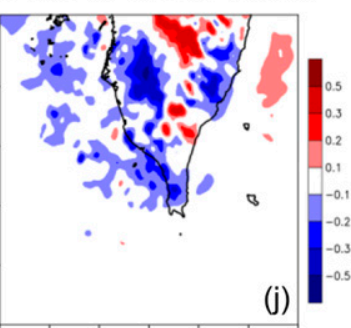

(j)

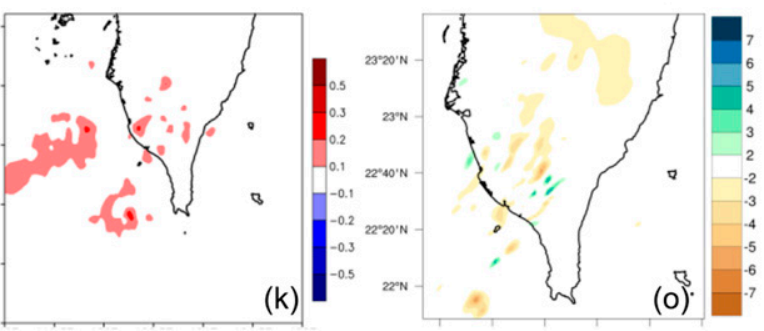

(k)

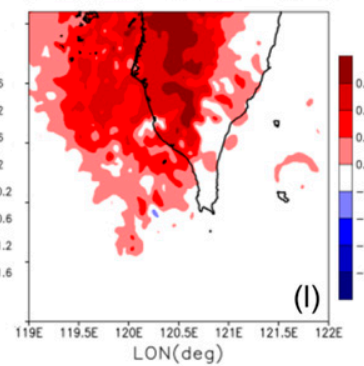

Precipitation ( $\mathrm{mm})$
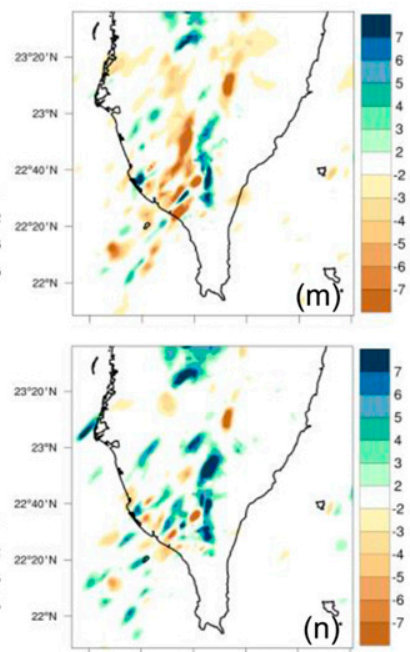

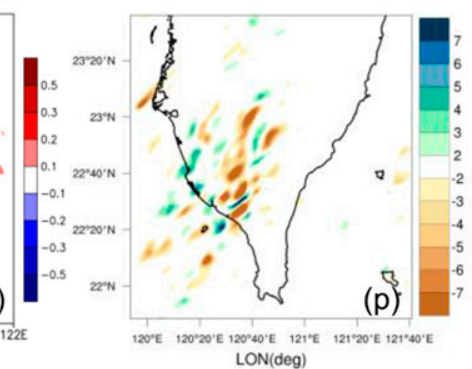

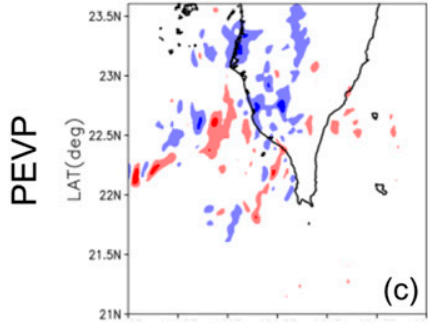

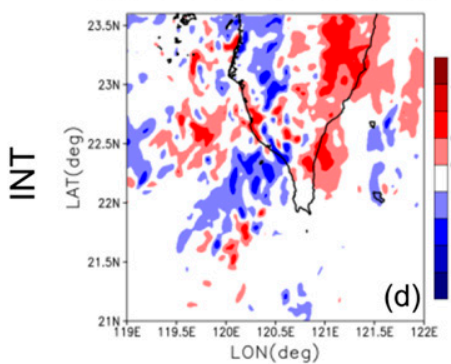

FIG. 18. Differences in (a)-(d) zonal wind $\left(\mathrm{m} \mathrm{s}^{-1}\right)$, (e)-(h) temperature $\left({ }^{\circ} \mathrm{C}\right)$, (i)-(l) pressure (hPa), and (m)-(p) 2-h (from 1100 to 1300 UTC) accumulated precipitation ( $\mathrm{mm}$ ) under (from top to bottom) different processes TEREVP, PTER, PEVP, and INT, respectively. The results are displayed over the terrain-following surface.

rainfall reduction. The latter (INT) is able to compensate for the rainfall increase caused by PTER over the southwestern plain. The contribution from pure evaporation (PEVP) is still relatively smaller than PTER or INT, which is consistent with the conclusions reached by analyzing the temperature and pressure difference fields.

\section{c. Averaged differences along the $y$ axis crossing the mountains}

The vertical distributions of the difference fields between the two experiments are investigated by averaging the fields along the $y$ axis, and exhibiting them over an $x-z$ vertical cross section. To compute the average, a range from the 140th to 200th grid along the $y$ direction (corresponding to the region from $22.5^{\circ}$ to $23.6^{\circ} \mathrm{N}$ as mentioned in section $7 \mathrm{~b}$ ) is first determined, which covers most of the CMR. The difference fields are obtained by performing a point-to-point subtraction between two experiments. Along the $y$ axis, if the number of grids located above the terrain is more than $50 \%$ of the total number (which is 46 ), the average along the $y$ axis is computed and displayed, as shown in Fig. 19. Otherwise, a value representing missing data is given, and is shown in the figure as terrain.

Figures 19a-d depict the differences in the $u$-wind and vertical velocity. In TEREVP (Fig. 19a), the major response to the existence of the CMR occurs not only near 

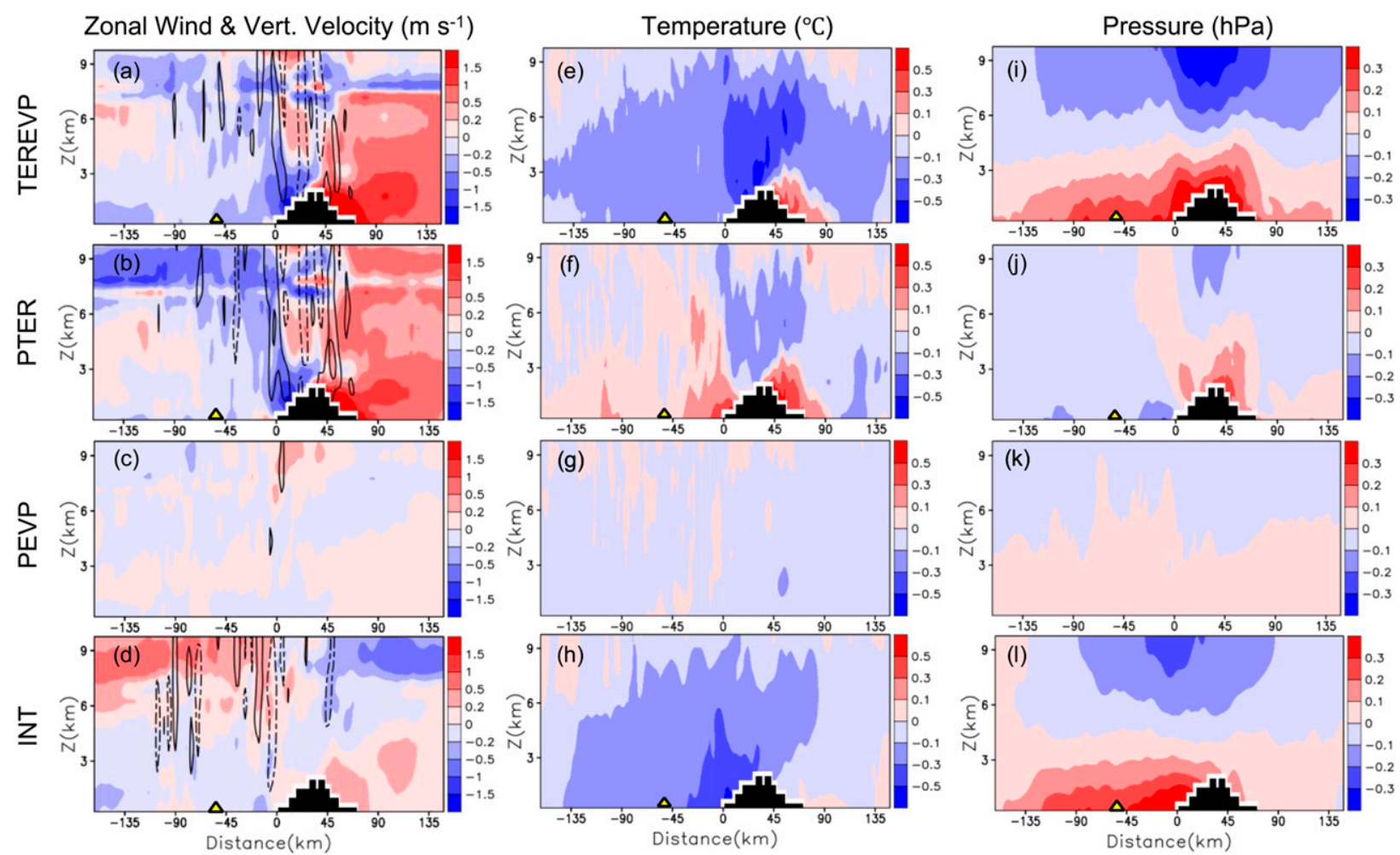

FIG. 19. Differences in (a)-(d) zonal wind and vertical velocity $\left(\mathrm{m} \mathrm{s}^{-1}\right),(\mathrm{e})-(\mathrm{h})$ temperature $\left({ }^{\circ} \mathrm{C}\right)$, and (i)-(l) pressure (hPa) under (from top to bottom) different processes TEREVP, PTER, PEVP, and INT, respectively. In (a)-(d) the vertical wind is shown by contours for \pm 0.1 and $\pm 0.3 \mathrm{~m} \mathrm{~s}^{-1}$ with negative values indicated by dashed lines. Each field is an average along the $y$ axis and displayed over a vertical cross section. The $x$ axis shows the relative distance $(\mathrm{km})$ from the foothills of the CMR on the windward side, with a triangle representing the coastline.

the mountains, but also extends to higher altitudes. Significant wind deceleration and acceleration take place along the mountain slope on the windward and leeward sides of the CMR, respectively. Similar features can also be found in PTER (Fig. 19b), indicating that the topographic effect is the dominant factor modulating the flow structure. With consideration of the evaporation process, PEVP and INT (Figs. 19c,d) also contribute to the development of deceleration and acceleration on the western and eastern side of the CMR, respectively, but with weaker magnitudes compared to that of PTER.

Figure 19b illustrates that PTER is still the dominant factor in determining the structure of the vertical velocity field, but the contribution from the nonlinear interaction INT is not negligible (Fig. 19d). Note that near $X=0 \mathrm{~km}$, an enhanced upward motion is observed in TEREVP and PTER (positive contour lines in Figs. 19a,b), apparently a direct response to the wind deceleration. By contrast, an enhanced downward motion at the same location, reaching a height of $9 \mathrm{~km}$, is present in INT (negative contour lines in Fig. 19d).

Another notable phenomenon can be identified in PTER (Fig. 19b) and INT (Fig. 19d) above $Z=8 \mathrm{~km}$, which is also the echo top height reached by existing convection. It is clearly shown that in PTER, a divergent type of flow is enhanced at the upper levels. This is a response to the low-level horizontal deceleration (thus convergence) caused by topographic blockage near $X=0 \mathrm{~km}$ (Fig. 19b), and is consistent with the enhanced vertical velocity at the same location. However, Fig. 19d also shows that in INT, an enhanced convergent type of flow is found at the upper levels, associated with the enhanced downward motion in INT at the same location. It can be inferred that the existence of the CMR triggers upward motion along the windward slope. The lifted airflow becomes divergent when it reaches a higher altitude $(\sim 8 \mathrm{~km})$. By contrast, with the evaporation process included in the nonlinear interaction with the terrain, a cooling effect contributes to the development of the downward motion, especially on the windward side of the CMR, which then strengthens the convergent flow at the upper levels.

The temperature differences generated by PTER and shown in Fig. 19f reveal that the mountains cause warming on both sides of the CMR and cooling above 
the mountain top. However, the nonlinear interaction term INT (Fig. 19h) tends to generate a significant cooling effect almost everywhere, with the strongest cooling taking place on the foothill near $X=0 \mathrm{~km}$. As a result, the total effect TEREVP shows that the cooling effect occupies a large portion of the domain, except along the leeside slope of the CMR (Fig. 19e). The pressure difference shown in Fig. 19i suggests the building of an enhanced high pressure zone near the mountains which stretches upstream nearly $100 \mathrm{~km}$ west of the CMR, mainly induced by nonlinear interaction INT (see Fig. 191). This enhanced high pressure zone exhibits resistance to the southwesterly flow, resulting in wind deceleration, helping to maintain a coastal convergence, as discussed in section 7. This long-lasting convergence provides favorable conditions supporting the convection near the southwestern coast of Taiwan.

\section{d. Sensitivity of rain-evaporative process}

Since the microphysical processes in a numerical model contain uncertainty, to confirm that the mechanisms concluded in previous sections remain valid with a different evaporation intensity, a new experiment YT10E is constructed in which the evaporation in the model is amplified to 10 times larger than that in YT1E. Through the following derivation, it can be shown that

$$
\begin{aligned}
\mathrm{EVP} 10-\mathrm{EVP} & =(\mathrm{YT} 10 \mathrm{E}-\mathrm{YT0E})-(\mathrm{YT} 1 \mathrm{E}-\mathrm{YT} 0 \mathrm{E}) \\
& =\mathrm{YT} 10 \mathrm{E}-\mathrm{YT} 1 \mathrm{E},
\end{aligned}
$$

where EVP10 is the difference between YT10E and YT0E. The difference obtained by subtracting YT1E from YT10E also represents the additional impact from stronger evaporation on the analytical results obtained through the nonlinear interaction between the terrain and evaporation (i.e., INT) and a pure evaporation process (i.e., PEVP). Figure 20 demonstrates that all of the features discussed in the previous sections are amplified as the intensity of the evaporation is increased. For example, over the southwestern plain, there is a significant reduction in the $u$ component of the wind, as shown in Figs. 20a and 20d. The atmosphere becomes colder in YT10E, from the mountain ridges to the coastal area (Figs. 20b,e), associated with an enhanced widespread high pressure zone covering almost the entire island (Figs. 20c,f). The zonal wind in YT10E is weakened, particularly on the windward side of the CMR. This can be explained by the enhanced cooling effect associated with the stronger evaporation in YT10E. The pressure difference leads to an additional wind speed deceleration toward the CMR at low levels in YT10E. It is worth mentioning that (YT10E - YT1E) can also be considered as another way to demonstrate the effect of INT, since both the terrain and evaporation are present in the model, but with the latter greatly amplified. By comparing the results depicted in Figs. 18-20, one can identify the similarity between the signals shown by INT and in (YT10E - YT1E).

\section{e. Schematic diagrams}

Two schematic diagrams are formulated and displayed in Figs. 21 and 22 to illustrate the basic mechanisms behind this heavy rainfall event. As the warm and moist prefrontal southwesterly flow from the ocean is lifted when it makes landfall and is blocked by the CMR, a local circulation system is initiated. Precipitation begins, leading to evaporative cooling of the air near the surface. A persistent surface convergence zone lies along the coast (see Fig. 12; and light yellow area in Fig. 21), due to the confluence between the southwesterly flow from the ocean (represented by the thick red arrows in Fig. 21) and the shallow (below $0.4 \mathrm{~km}$ ) offshore flow over the southwestern plain (see Fig. 13; and thick blue arrows in Fig. 21). When the prefrontal rainband (marked by B in Fig. 4) passes the coastal convergence line (represented by the black dashed lines in Fig. 21), the existing convective cells embedded in the rainband are further enhanced by the low-level convergence (marked with brown in Fig. 21 and the circled "1" in Fig. 22), resulting in a strengthening of the upward motion (see Fig. 14c, and the circled "2" in Fig. 22). The strengthened convection then grows vertically, and an enhanced divergent outflow is analyzed at about $Z \sim 8 \mathrm{~km}$ (circled "3" in Fig. 22). The airflow travels to the CMR, where downdrafts are found over the CMR and along the mountain slopes (see Fig. 14c and the circled "4" in Fig. 22). At the foothills of the CMR (circled "5" in Fig. 22), the evaporative cooling effect associated with the downdrafts creates a tendency to increase the pressure, which tends to resist the incoming southwesterly flow, leading to the very shallow offshore wind component observed only by mesonet and radiosonde under $Z=0.4 \mathrm{~km}$ (see Figs. 13 and 16b, and the circled " 6 " in Fig. 22). Mountain blockage and the nonlinear interaction between the terrain and evaporation play important roles in maintaining this quasi-stationary coastal convergence line, leading to this long-lasting heavy precipitation event.

\section{Conclusions and future work}

This case study represents the first attempt at using IBM_VDRAS to assimilate real observations and conduct computation with topography in both forward and 

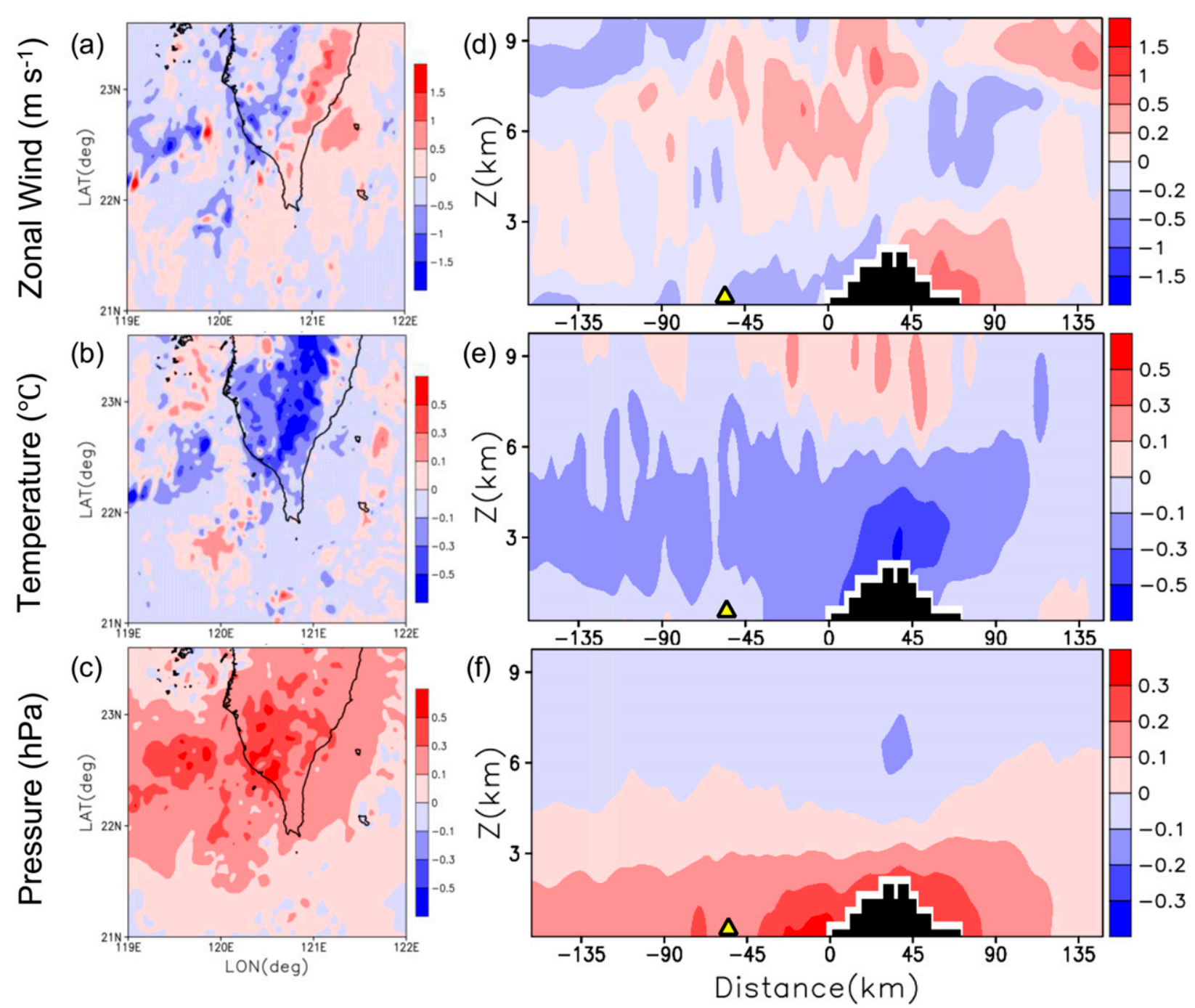

FIG. 20. The differences from the "YT10E-YT1E" experiment for the fields for (a), (d) zonal wind (m s $\left.{ }^{-1}\right)$; (b), (e) temperature $\left({ }^{\circ} \mathrm{C}\right)$; and (c),(f) pressure (hPa). (a)-(c) The results on a terrain-following surface, and (d)-(f) the average values along the $y$ axis and over a vertical cross section. The small triangle on the $x$ axis indicates the location of the coastline.

adjoint models. The purpose is to understand the mechanisms behind a heavy rainfall event that took place during 2008 SoWMEX in Taiwan. The major findings and conclusions are listed as follows:

1) Comprehensive evaluations show that the kinematic and thermodynamic fields retrieved by IBM_VDRAS are in good agreement with various types of independent measurements from mesonet stations, radiosonde, and wind profiler.

2) The warm and moist southwesterly flow from the warm ocean decelerates after making landfall and is blocked when reaching the CMR, leading to precipitation and enhancement of evaporative cooling associated with high pressure near the mountains. Due to the confluence of the decelerated southwesterly flow and a very shallow layer (below $0.4 \mathrm{~km}$ ) of offshore flow induced by evaporative cooling near the CMR, a quasi-stationary surface convergence zone forms along the coast, which provides favorable conditions for the development of convection and helps to maintain the rainfall system.

3) The major mechanisms leading to the formation and maintenance of this rainfall system are decomposed into the pure topographic (PTER), pure evaporation cooling (PEVP), and the nonlinear interactive effect (INT). PTER is found to be the dominant factor modulating the flow structure, and it is the nonlinear interaction between terrain and evaporation (INT) that determines the distribution of the temperature and pressure fields. PTER tends to induce a rainfall increase along the western slope of the CMR and 


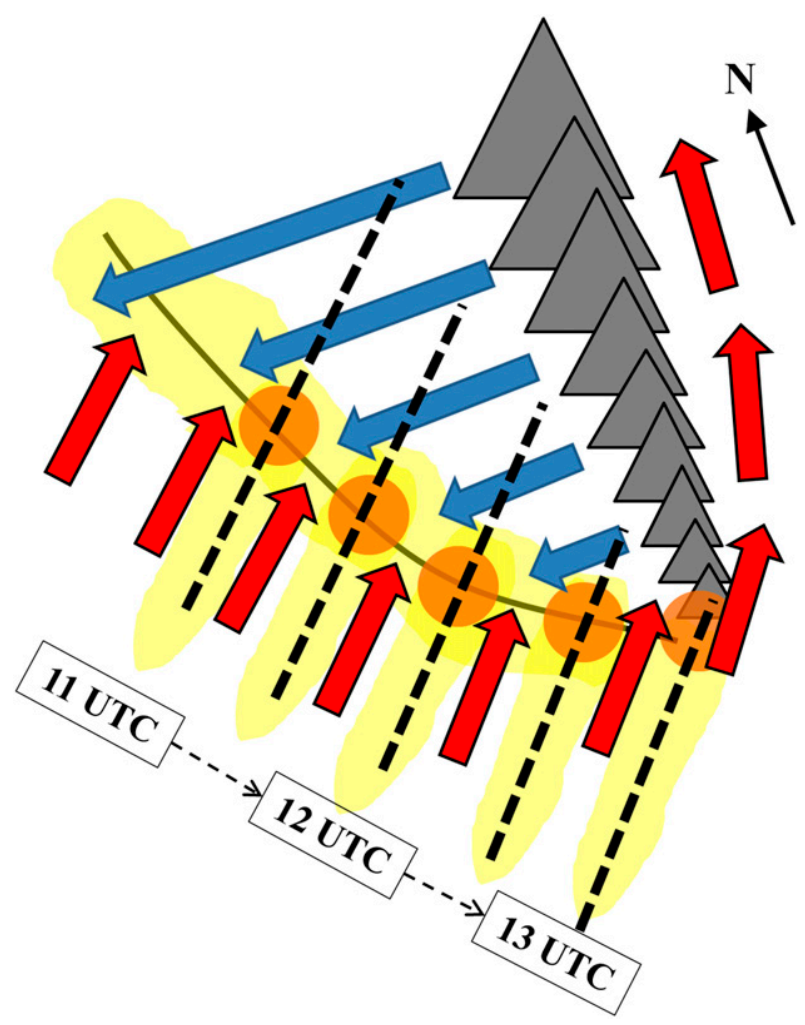

FIG. 21. Schematic diagram showing the structure of the rainfall event. The gray-filled triangles represent the CMR and the thick solid curve indicates the coastline of southwestern Taiwan. The arrows indicate the directions of the surface wind, with red (blue) representing relatively warmer (colder) temperatures. The light yellow area shows the convergence area revealed by IBM_VDRAS analyses. The black dashed lines depict the movement of rainband $B$ at different stages with the times shown below them. The brown circled areas mark the locations with enhanced convergence.

part of the southwestern plain, while INT is inclined to cause a rainfall decrease over the southwestern plain. The latter (INT) is able to compensate for the rainfall increase caused by PTER over the southwestern plain. The contribution from pure evaporation (PEVP) is still relatively smaller than PTER or INT, which is consistent with the conclusion reached by analyzing the temperature and pressure difference fields.

With the implementation of its terrain-resolving capability, it is expected that IBM_VDRAS will improve analysis of high impact weather as well as nowcasting in regions with significant topographic forcing. In terms of further improvement of IBM_VDRAS, a planned future development is to design a new scheme so that it can directly assimilate surface data measured by instruments such as mesonet stations, buoys, and satellite-derived ocean surface winds.

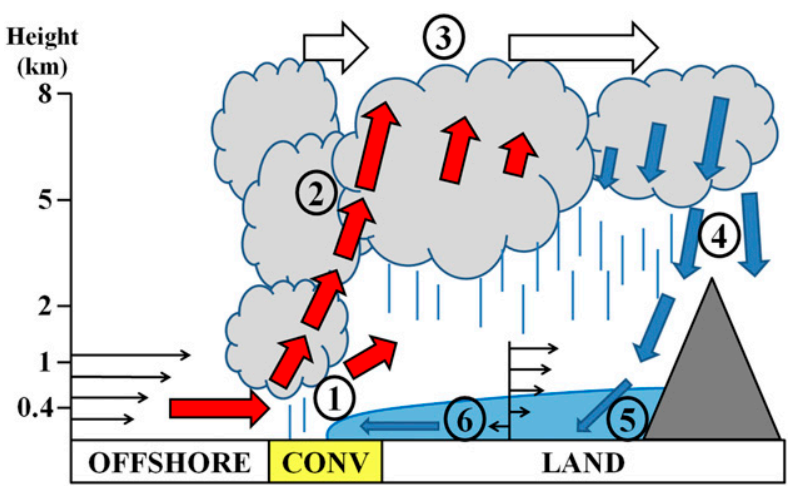

FIG. 22. Schematic diagram showing the rainfall processes from offshore (west) to the CMR (east). The $x$ axis marks the location of the land-sea contrast and the convergence zone. The $z$ axis shows the height. The thin black arrows represent the vertical profiles of the horizontal wind. The thick arrows depict the directions of the airflow, with red (blue) denoting a warmer (colder) temperature. The area near the foothill filled in with light blue indicates the low-level enhanced cooling zone due to the interactive effect between the terrain and evaporative cooling. The circled numbers show the locations of the associated phenomena mentioned in section 8 .

Acknowledgments. This research is supported by the Ministry of Science and Technology of Taiwan under MOST107-2111-M-008-040, MOST107-2625-M-008008, and by the Central Weather Bureau under MOTCCWB-107-M-02.

\section{REFERENCES}

Ballard, S. P., Z. Li, D. Simonin, and J.-F. Caron, 2016: Performance of 4D-Var NWP-based nowcasting of precipitation at the Met Office for summer 2012. Quart. J. Roy. Meteor. Soc., 142, 472-487, https://doi.org/10.1002/qj.2665.

Bougeault, P., and Coauthors, 2001: The MAP Special Observing Period. Bull. Amer. Meteor. Soc., 82, 433-462, https://doi.org/ 10.1175/1520-0477(2001)082<0433:TMSOP > 2.3.CO;2.

Chang, S.-F., J. Sun, Y.-C. Liou, S.-L. Tai, and C.-Y. Yang, 2014: The influence of erroneous background, beam-blocking and microphysical non-linearity on the application of a fourdimensional variational Doppler radar data assimilation system for quantitative precipitation forecasts. Meteor. Appl., 21, 444-458, https://doi.org/10.1002/met.1439.

_ , Y.-C. Liou, J. Sun, and S.-L. Tai, 2016: The implementation of the ice phase microphysical process into a four-dimensional Variational Doppler Radar Analysis System (VDRAS) and its impact on parameter retrieval and quantitative precipitation nowcasting. J. Atmos. Sci., 73, 1015-1038, https://doi.org/ 10.1175/JAS-D-15-0184.1.

Chang, W.-Y., W.-C. Lee, and Y.-C. Liou, 2015: The kinematic and microphysical characteristics and associated precipitation efficiency of subtropical convection during SoWMEX/ TiMREX. Mon. Wea. Rev., 143, 317-340, https://doi.org/10.1175/ MWR-D-14-00081.1.

Chen, C.-S., Y.-L. Lin, H.-T. Zeng, C.-Y. Chen, and C.-L. Liu, 2013: Orographic effects on heavy rainfall events over northeastern Taiwan during the northeasterly monsoon season. Atmos. Res. 122, 310-335, https://doi.org/10.1016/j.atmosres.2012.10.008. 
Chen, S.-H., and Y.-L. Lin, 2005: Orographic effects on a conditionally unstable flow over an idealized three-dimensional mesoscale mountain. Meteor. Atmos. Phys., 88, 1-21, https:// doi.org/10.1007/s00703-003-0047-6.

Crook, A., and J. Sun, 2002: Assimilating radar, surface, and profiler data for the Sydney 2000 forecast demonstration project. J. Atmos. Oceanic Technol., 19, 888-898, https://doi.org/ 10.1175/1520-0426(2002)019<0888:ARSAPD>2.0.CO;2.

—_, and — 2004: Analysis and forecasting of the low-level wind during the Sydney 2000 forecast demonstration project. Wea. Forecasting, 19, 151-167, https://doi.org/10.1175/15200434(2004)019<0151:AAFOTL > 2.0.CO;2.

Davis, C. A., and W.-C. Lee, 2012: Mesoscale analysis of heavy rainfall episodes from SoWMEX/TiMREX. J. Atmos. Sci., 69, 521-537, https://doi.org/10.1175/JAS-D-11-0120.1.

Friedrich, K., E. Kalina, J. Aikins, M. Steiner, D. Gochis, P. Kurera, K. Ikeda, and J. Sun, 2016: Raindrop size distribution and rain characteristics during the 2013 Great Colorado Flood. J. Hydrometeor., 17, 53-72, https://doi.org/10.1175/JHM-D-140184.1.

Gochis, D., and Coauthors, 2015: The great Colorado flood of September 2013. Bull. Amer. Meteor. Soc., 96, 1461-1487, https://doi.org/10.1175/BAMS-D-13-00241.1.

Hayden, C. M., and R. J. Purser, 1995: Recursive filter objective analysis of meteorological fields: Applications to NESDIS operational processing. J. Appl. Meteor., 34, 3-15, https:// doi.org/10.1175/1520-0450-34.1.3.

Houze, R. A., Jr., 2012: Orographic effects on precipitating clouds. Rev. Geophys., 50, RG1001, https://doi.org/10.1029/ 2011RG000365.

Kawabata, T., T. Kuroda, H. Seko, and K. Saito, 2011: A cloud resolving 4DVAR assimilation experiment for a local heavy rainfall event in the Tokyo metropolitan area. Mon. Wea. Rev., 139, 1911-1931, https://doi.org/10.1175/ 2011MWR3428.1.

Kessler, E., 1969: On the Distribution and Continuity of Water Substance in Atmospheric Circulation. Meteor. Monogr., No. 32, Amer. Meteor. Soc., 84 pp.

Lai, H.-W., C. A. Davis, and B. J.-D. Jou, 2011: A subtropical oceanic mesoscale convective vortex observed during SoWMEX/TiMREX. Mon. Wea. Rev., 139, 2367-2385, https:// doi.org/10.1175/2010MWR3411.1.

Lim, E., and J. Sun, 2010: A velocity dealiasing technique using rapidly updated analysis from a four-dimensional variational Doppler radar data assimilation system. J. Atmos. Oceanic Technol., 27, 1140-1152, https://doi.org/10.1175/ 2010JTECHA1300.1.

Lin, Y.-L., S. Chiao, T.-A. Wang, M. L. Kaplan, and R. P. Weglarz, 2001: Some common ingredients for heavy orographic rainfall. Wea. Forecasting, 16, 633-660, https://doi.org/10.1175/15200434(2001)016<0633:SCIFHO > 2.0.CO;2.

Liou, Y.-C., and Y.-J. Chang, 2009: A variational multiple-Doppler radar three-dimensional wind synthesis method and its impact on thermodynamic retrieval. Mon. Wea. Rev., 137, 3992-4010, https://doi.org/10.1175/2009MWR2980.1.

Lundquist, K. A., F. K. Chow, and J. K. Lundquist, 2010: An immersed boundary method for the Weather Research and Forecasting model. Mon. Wea. Rev., 138, 796-817, https:// doi.org/10.1175/2009MWR2990.1.

Markowski, P., and Y. Richardson, 2010: Mesoscale Meteorology in Midlatidudes. John Wiley \& Sons, 407 pp.

Menchaca, M. Q., and D. R. Durran, 2017: Mountain waves, downslope winds, and low-level blocking forced by a midlatitude cyclone encountering an isolated ridge. J. Atmos. Sci., 74, 617-639, https://doi.org/10.1175/JAS-D-16-0092.1.

Mohd-Yusof, J., 1997: Combined immersed boundary/B-spline methods for simulations of flow in complex geometry. Center for Turbulence Research, Annual Research Briefs, NASA Ames/Stanford University, 11 pp., https://web.stanford.edu/ group/ctr/ResBriefs97/myusof.pdf.

Roe, G. H., 2005: Orographic precipitation. Annu. Rev. Earth Planet. Sci., 33, 645-671, https://doi.org/10.1146/ annurev.earth.33.092203.122541.

Rotunno, R., and R. A. Houze Jr., 2007: Lessons on orographic precipitation from the Mesoscale Alpine Programme. Quart. J. Roy. Meteor. Soc., 133, 811-830, https://doi.org/10.1002/qj.67.

Smith, R. B., and I. Barstad, 2004: A linear theory of orographic precipitation. J. Atmos. Sci., 61, 1377-1391, https://doi.org/ 10.1175/1520-0469(2004)061<1377:ALTOOP>2.0.CO;2.

Sun, J., 2005: Initialization and numerical forecasting of a supercell storm observed during STEPS. Mon. Wea. Rev., 133, 793-813, https://doi.org/10.1175/MWR2887.1.

__ , and N. A. Crook, 1997: Dynamic and microphysical retrieval from Doppler radar observations using a cloud model and its adjoint. Part I: Model development and simulated data experiment. J. Atmos. Sci., 54, 1642-1661, https://doi.org/10.1175/1520-0469(1997)054<1642:DAMRFD> 2.0.CO;2.

— analysis using single WSR-88D data. Wea. Forecasting, 16, 117-132, https://doi.org/10.1175/1520-0434(2001)016<0117: RTLLWA $>2.0 . \mathrm{CO} ; 2$.

- , and Y. Zhang, 2008: Analysis and prediction of a squall line observed during IHOP using multiple WSR-88D observations. Mon. Wea. Rev., 136, 2364-2388, https://doi.org/10.1175/ 2007MWR2205.1.

, and H. Wang, 2013: Radar data assimilation with WRF 4DVar. Part II: Comparison with 3D-Var for a squall line over the U.S. Great Plains. Mon. Wea. Rev., 141, 2245-2264, https:// doi.org/10.1175/MWR-D-12-00169.1.

_- M. Chen, and Y. Wang, 2010: Frequent-updating analysis system based on radar, surface, and mesoscale model data for the Beijing 2008 Forecast Demonstration Project. Wea. Forecasting, 25, 1715-1735, https://doi.org/10.1175/ 2010WAF2222336.1.

Tai, S.-L., Y.-C. Liou, J. Sun, S.-F. Chang, and M.-C. Kuo, 2011: Precipitation forecasting using Doppler radar data, a cloud model with adjoint, and the Weather Research and Forecasting model: Real case studies during SoWMEX in Taiwan. Wea. Forecasting, 26, 975-992, https://doi.org/ 10.1175/WAF-D-11-00019.1.

_ $-\longrightarrow,-$, and — 2017: The development of a terrainresolving scheme for the forward model and its adjoint in the four-dimensional Variational Doppler Radar Analysis System (VDRAS). Mon. Wea. Rev., 145, 289-306, https://doi.org/ 10.1175/MWR-D-16-0092.1.

Tseng, Y., and J. Ferziger, 2003: A ghost-cell immersed boundary method for flow in complex geometry. J. Comput. Phys., 192, 593-623, https://doi.org/10.1016/j.jcp.2003.07.024.

Tu, C.-C., Y.-L. Chen, S.-Y. Chen, Y.-H. Kuo, and P.-L. Lin, 2017: Impacts of including rain-evaporative cooling in the initial conditions on the prediction of a coastal heavy rainfall event during TiMREX. Mon. Wea. Rev., 145, 253-277, https:// doi.org/10.1175/MWR-D-16-0224.1.

Wang, H., J. Sun, X. Zhang, X. Huang, and T. Auligne, 2013: Radar data assimilation with WRF 4D-Var. Part I: System development 
and preliminary testing. Mon. Wea. Rev., 141, 2224-2244, https:// doi.org/10.1175/MWR-D-12-00168.1.

Weckwerth, T. W., L. J. Bennett, L. J. Miller, J. V. Baelen, P. D. Girolamo, A. M. Blyth, and T. J. Hertneky, 2014: An observational and modeling study of the processes leading to deep, moist convection in complex terrain. Mon. Wea. Rev., 142, 2687-2708, https://doi.org/10.1175/MWR-D-13-00216.1.

Wulfmeyer, V., and Coauthors, 2011: The Convective and Orographically-induced Precipitation Study (COPS): The scientific strategy, the field phase, and research highlights.
Quart. J. Roy. Meteor. Soc., 137, 3-30, https://doi.org/ 10.1002/qj.752.

Xu, W., E. J. Zipser, Y.-L. Chen, C. Liu, Y.-C. Liou, W.-C. Lee, and B. J.-D. Jou, 2012: An orography-associated extreme rainfall event during TiMREX: Initiation, storm evolution, and maintenance. Mon. Wea. Rev., 140, 2555-2574, https:// doi.org/10.1175/MWR-D-11-00208.1.

Yamazaki, H., and T. Satomura, 2010: Nonhydrostatic atmospheric modeling using a combined Cartesian grid. Mon. Wea. Rev., 138, 3932-3945, https://doi.org/10.1175/2010MWR3252.1. 